FHWA/IN/JTRP-2009/5

Final Report

MULTI-JURISDICTIONAL ISSUES RELATED TO CONGESTION MANAGEMENT

Jon D. Fricker

Myron Matlock

April 2009 
Final Report

FHWA/IN/JTRP-2009/5

\title{
Multi-Jurisdictional Issues Related to Congestion Management
}

\author{
by \\ Myron Matlock \\ Graduate Research Assistant \\ and \\ Prof. Jon D. Fricker \\ Principal Investigator \\ School of Civil Engineering \\ Purdue University \\ Joint Transportation Research Program \\ Project No. C-36-74G \\ File No. 3-9-7 \\ SPR-3097 \\ Conducted in Cooperation with the \\ Indiana Department of Transportation \\ and the \\ U.S. Department of Transportation \\ Federal Highway Administration
}

The contents of this report reflect the views of the authors, who are responsible for the facts and the accuracy of the data presented herein. The contents do not necessarily reflect the official views or policies of the Indiana Department of Transportation or the Federal Highway Administration at the time of publication. The report does not constitute a standard, specification, or regulation.

\author{
Purdue University \\ West Lafayette, IN 47907
}

April 2009 
TECHNICAL REPORT STANDARD TITLE PAGE

\begin{tabular}{|c|c|c|}
\hline $\begin{array}{l}\text { 1. Report No. } \\
\text { FHWA/IN/JTRP-2009/5 }\end{array}$ & 2. Government Accession No. & 3. Recipient's Catalog No. \\
\hline \multirow{2}{*}{\multicolumn{2}{|c|}{$\begin{array}{l}\text { 4. Title and Subtitle } \\
\text { Jurisdictional Issues Related to Congestion Management }\end{array}$}} & $\begin{array}{l}\text { 5. } \text { Report Date } \\
\text { April } 2009\end{array}$ \\
\hline & & 6. Performing Organization Code \\
\hline \multicolumn{2}{|l|}{$\begin{array}{l}\text { 7. Author(s) } \\
\text { Jon D. Fricker and Myron Matlock }\end{array}$} & $\begin{array}{l}\text { 8. Performing Organization Report No. } \\
\text { FHWA/IN/JTRP-2009/5 }\end{array}$ \\
\hline \multicolumn{2}{|l|}{$\begin{array}{l}\text { 9. Performing Organization Name and Address } \\
\text { Joint Transportation Research Program } \\
1284 \text { Civil Engineering Building } \\
\text { Purdue University } \\
\text { West Lafayette, IN 47907-1284 }\end{array}$} & 10. Work Unit No. \\
\hline \multicolumn{2}{|l|}{$\begin{array}{l}\text { 12. Sponsoring Agency Name and Address } \\
\text { Indiana Department of Transportation } \\
\text { State Office Building } \\
100 \text { North Senate Avenue } \\
\text { Indianapolis, IN } 46204\end{array}$} & 14. Sponsoring Agency Code \\
\hline \multicolumn{3}{|l|}{ 15. Supplementary Notes } \\
\hline
\end{tabular}

\section{Abstract}

When a project intended to solve transportation problems such as congestion and access management involves multiple cities, counties, and/or state agencies, disputes can occur due to incompatible interests, resulting in project delays. Creating a mechanism that allows the agencies to communicate and work together during the planning stages can improve the effectiveness of the final plan for the project.

The purpose of this study was to develop and provide transportation agencies with coordination and collaborative strategies that could be used to help the various agencies work together on multiple projects. This study was based on a study of the literature in disciplines such as economics, management, and social sciences to investigate collaborative structures and management strategies.

Collaboration that involves cities, counties and/or state agencies would use a forum discussion to discuss issues and formulate transportation project solutions on an ad hoc basis, allowing for flexibility from case to case. These organizations would manage the process using the jurisdictional-based model, where an agency such as the MPO would serve as the coordinator between jurisdictions during the planning process.

\begin{tabular}{|c|c|c|c|c|}
\hline \multicolumn{2}{|c|}{$\begin{array}{l}\text { 17. Key Words } \\
\text { Collaboration, coordination, jurisdiction, stakeholders }\end{array}$} & \multicolumn{3}{|c|}{$\begin{array}{l}\text { 18. Distribution Statement } \\
\text { No restrictions. This document is available to the public through the } \\
\text { National Technical Information Service, Springfield, VA } 22161\end{array}$} \\
\hline $\begin{array}{l}\text { 19. Security Classif. (of this report) } \\
\text { Unclassified }\end{array}$ & \multicolumn{2}{|c|}{$\begin{array}{c}\text { 20. Security Classif. (of this page) } \\
\text { Unclassified }\end{array}$} & $\begin{array}{r}\text { 21. No. of Pages } \\
90\end{array}$ & 22. Price \\
\hline
\end{tabular}

Form DOT F 1700.7 (8-69) 
TABLE OF CONTENTS

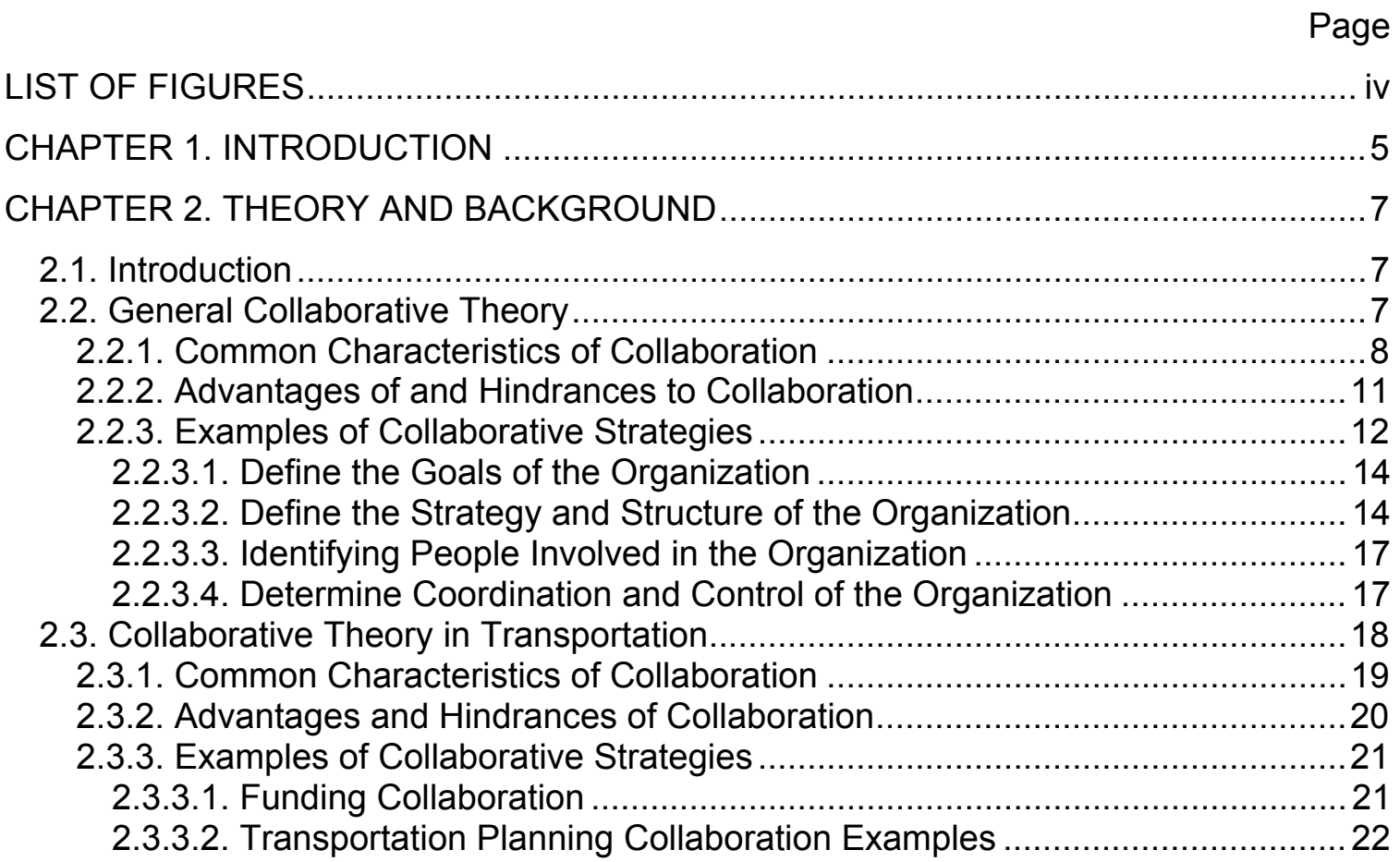

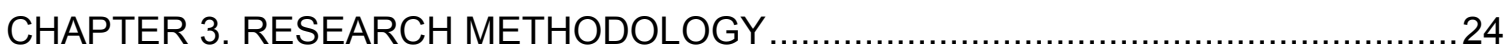

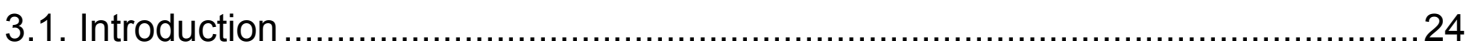

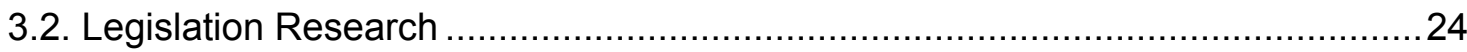

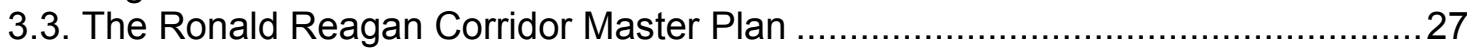

3.4. Transportation Collaboration Examples........................................................ 30

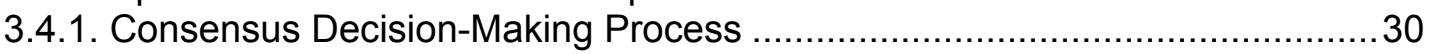

3.4.2. Transportation Collaboration in Other States............................................ 31

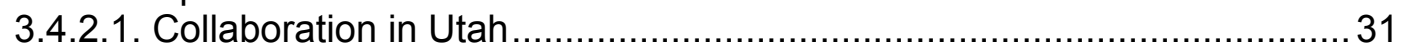

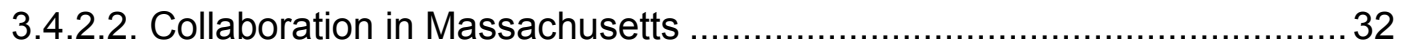

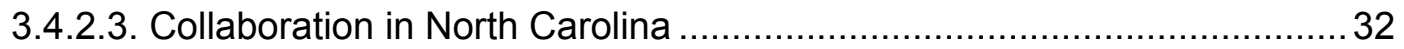

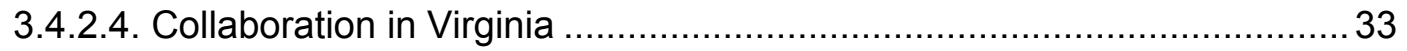

3.4.2.5. Common Collaborative Themes from NPCC ….................................. 33

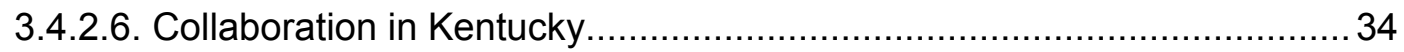

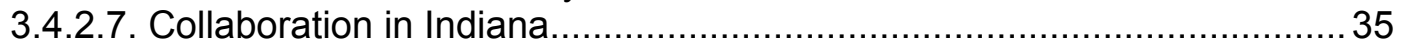

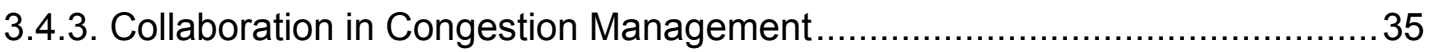

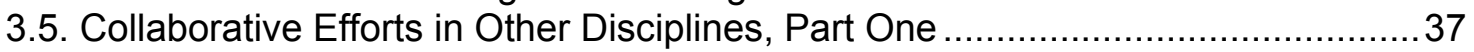

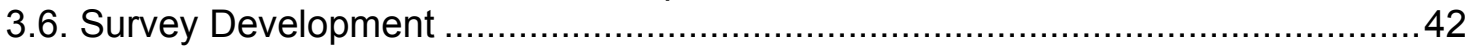

3.7. Collaborative Efforts in Other Disciplines, Part Two ....................................... 44

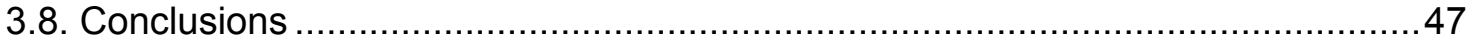


CHAPTER 4. COLLABORATIVE STRUCTURES AND MANAGEMENT TYPES 49

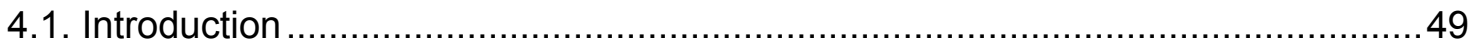

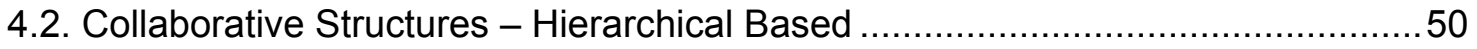

4.2.1. Formalized, Hierarchical Based Structures........................................ 50

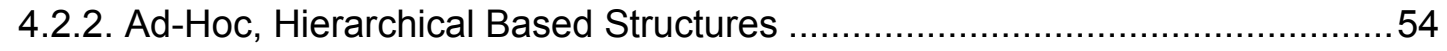

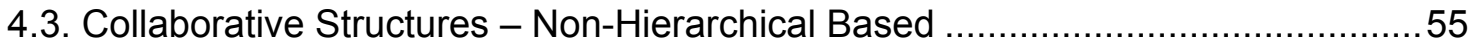

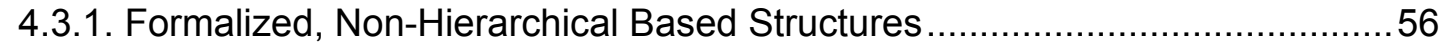

4.3.2. Ad-Hoc, Non Hierarchical Based Structures ............................................ 58

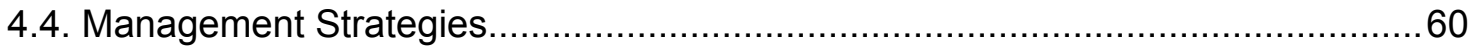

4.4.1. Traditional, Top Bottom Management (Forward Mapping) Approach ............60 60

4.4.2. Bottom-Top Management (Backward Mapping) Approach ..........................61

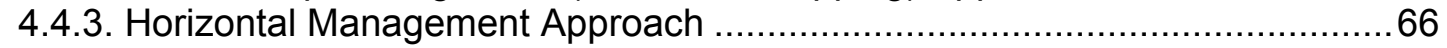

4.5. Organizational Structures and Management Applied to Transportation ...............68

4.6. Dispute Resolution Methods .................................................................... 71

4.7. Memoranda of Understanding in the Collaborative Process ............................... 71

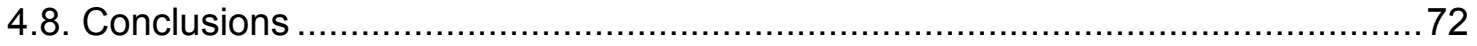

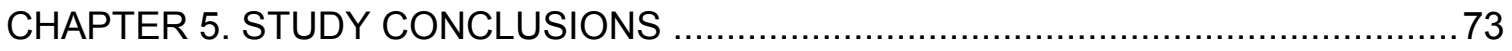

5.1. Suggested Collaborative Structure and Management Technique - MultiJurisdictional Issues Related to Congestion Management .................................73

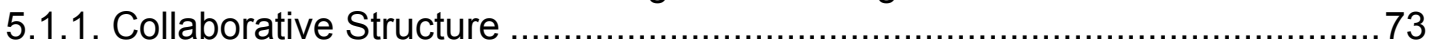

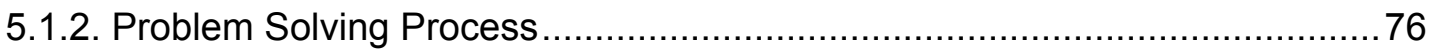

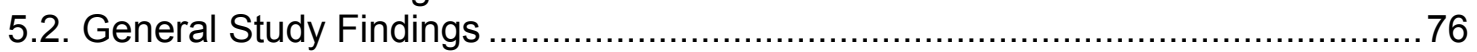

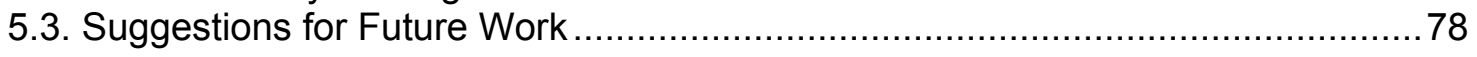

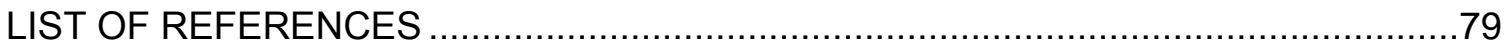




\section{LIST OF FIGURES}

Figure Page

Figure 3.1 Ronald Reagan Corridor Map ....................................................... 28

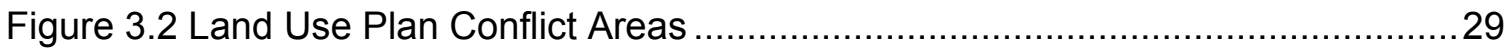

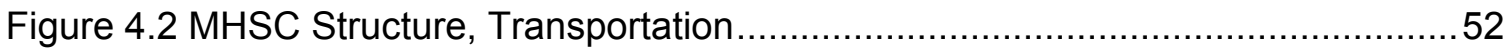

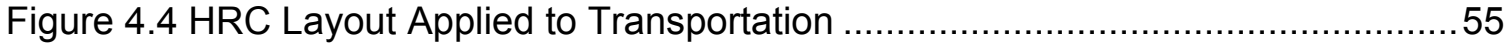

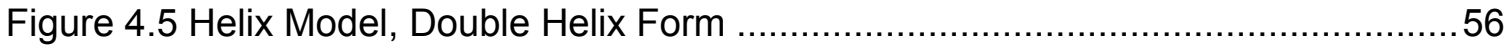

Figure 4.6 Potential WILMAPCO Subcommittee Layout............................................58

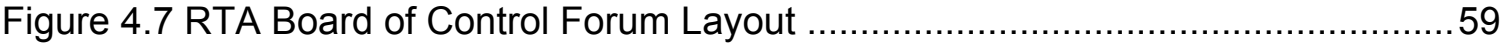

Figure 4.8 Forward Mapping Decision Process ................................................... 61

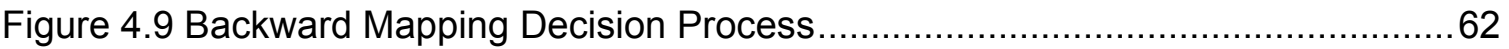

Figure 4.12 Jurisdictional-Based Model for Salem, Indiana ......................................67

Figure 4.13 Jurisdiction Based Model, Transportation ............................................... 68

Figure 4.18 Jurisdiction Communication Using the Helix Model ..................................69

Figure 5.1 Multi-Jurisdictional Collaborative Structure .......................................... 75

Figure 5.2 Long Range Planning Process for INDOT Projects .........Error! Bookmark not defined. 


\section{CHAPTER 1. INTRODUCTION}

In many projects, a team effort is necessary in order to achieve success. In the field of transportation planning, collaboration and coordination are usually required. Highway design, emergency response, and traffic signal timing all require some type of cooperation between agencies and jurisdictions. A successful project requires that multiple individuals discuss, organize, and approve a plan.

The purpose of this study is to investigate and determine the best strategies with which transportation officials can better coordinate and collaborate throughout various planning processes. This study involves determining the best ways of coordinating various jurisdictions such as INDOT, MPOs, and other agencies when dealing with congestion management issues. When planning a transportation project such as a roadway corridor, the perspectives of the involved parties such as the county, city, state, and federal governments may conflict with each other. An example of a project where conflicting issues could arise is the Ronald Reagan Parkway in Hendricks County, Indiana. Portions of this project have already been completed, with the entire project scheduled for completion in September, 2008 (Holmes, 2007; Plainfield, Indiana Department of Engineering, 2007). This parkway, which will connect Interstates 70 and 74 west of Indianapolis, Indiana, is located within four different jurisdictions that have varying land use interests. Each jurisdiction has created their own land use plans, and the plans are inconsistent in areas where the jurisdictions are adjacent to each other (HNTB and Hendricks County, 2005). In addition, a master land use plan was created, which also has conflict points with the plans developed by the jurisdictions. The inconsistencies in the plans may result in disputes, which can delay the project. A set of strategies can be useful to help avoid issues with transportation planning activities such as land use and access management. Establishing a series of guidelines to solve issues related to working with multiple jurisdictions would be helpful to avoid disputes and delays in transportation planning.

This study will use the results from literature reviews to determine what is required and what has already been tested in the field. The surveys of transportation 
officials will be used to determine common collaborative issues, and to identify other successful collaborative efforts. Consulting transportation officials will allow processes to be identified without significantly impeding on the teamwork strategies that already exist. At the conclusion of the project, a suggested list of ways to establish and maintain effective collaborative and coordinative efforts will be provided. 


\section{CHAPTER 2. THEORY AND BACKGROUND}

\subsection{Introduction}

In order to understand what strategies will be most effective during collaborative efforts between governmental organizations in multiple jurisdictions, it is necessary to understand the reasons why collaborative efforts are formed and determine typical collaborative structures. This analysis was conducted through a literature search that investigated coordinated and collaborative efforts in transportation and in other disciplines such as management, economics, and social sciences.

\subsection{General Collaborative Theory}

Collaboration and teamwork have been used for as long as civilization has existed. An example of one of the earliest American collaborative efforts occurred in 1783, when numerous merchants and insurance companies collaborated to establish America's shipping industry after access to the British market was closed following the American Revolutionary War (Lynch, 1989). Other examples of collaborative efforts in the United States include the crude oil drilling industry and international collaborative efforts such as the tire company Uniroyal collaborating with a Mexican organization so that they could be involved in the Mexican petrochemical business (Lynch, 1989).

The number of joint ventures and collaborative efforts has increased in the late $20^{\text {th }}$ century and early $21^{\text {st }}$ century. Collaborative efforts were formed in fields such as engineering, economics, management, automobiles, and the entertainment industry. 
Specifically, the number of collaborative efforts has increased since the 1980s (Lynch, 1989). One example of the earliest collaborative efforts during the emergence of joint ventures was the formation of TriStar Pictures, which was created through the efforts of CBS, Columbia Pictures, and Home Box Office (HBO). This particular venture was beneficial because the national broadcast company (CBS) now had an interest in the cable market, HBO acquired more films, and Columbia Pictures was able to use more of its filming space (Lynch, 1989). As more companies saw the benefits of collaborative efforts and joint ventures, they decided to take full advantage of the new opportunities.

\subsubsection{Common Characteristics of Collaboration}

In some cases, it may not be obvious why people and groups choose to work together. While there are different reasons to form collaborative organizations, some reasons are constant for everyone. Lynch (1989) provides the following reasons why collaborative efforts are formed: "hybridization", faster delivery of the product to market, and to overcome insufficient management and technical resources. A "hybridization" of technologies allows for production of the best overall product, especially if the collaborating organizations specialized in one expertise or profession. For example, a trucking manufacturer may be able to produce a quality truck, but may not have the resources to produce a new type of engine. As a result, the trucking company may work with another company that specializes in engine building to complete its product. Organizations may also discover that their existing management operations may not be adequate to manage a project due to insufficient management and technical resources. This can occur when new products are introduced and a competitor may already have experience in managing the product, or when a project requires expertise in a specific field. The example of the trucking company and engine supplier can be used for this case.

According to Lynch (1989), a joint venture can be structured informally or formally. In the informal venture, a separate organization is not created, and a loose confederation of people is assigned to coordinate the alliance's functions. In the formal 
"detached" organization, a separate organization is created and operated by the collaborating companies. This option is most effective for highly integrated management, long term commitments, and high levels of uncertainty. This option is also very effective when the joint venture pursues multiple projects.

Lynch (1989) also describes the characteristics of the detached organization, which is dependent on autonomy, support, and control. Specifically, there are three different pattern types of the detached organization that apply to this study:

- The dependent/captive venture, which supplies owners with products or materials. The joint venture is the distributing agency in the market place, and is heavily dependent on the owners.

- A co-dependent/constrained venture, where the partners maintain their own production facilities in their own organizations and in the partnership. This venture is most effective in a short transition period for organizations undergoing mergers.

- An interdependent/cooperative venture, where the venture's managers have the power to be entrepreneurial.

In addition to the venture types, Lynch also describes the leadership structure and compares project and goal orientation. In the joint venture, the organization should be led by a "champion" who believes in the organization and its goals, and whose goals are similar to those of the organization. The organization should have a steering committee whose purpose is to oversee the project and hold regularly scheduled meetings (Lynch, 1989). Lynch also defines the project oriented and the goal oriented organizations. The project oriented group has high levels of certainty and clarity, whereas the goal oriented venture is more focused on research and development.

Next, Lynch discusses the principles and practice of alliance management. Specifically, there are seven operational management principles:

- Effective leadership - management mix

- Using differentiation and integration 
- Ambiguity - certainty continuum (clarity in environment)

- Interface management

- Collaborative decision-making

- Managing cross corporate relations

- Personnel selection

In order to achieve an effective leadership - management mix, the organization's "champions" should be identified. The "champions" serve as the connection between joint ventures and the parent company. The joint venture should include have product and executive "champions." The product "champions" defend the new collaboration, and must show leadership skills. The executive "champions" are located in the next higher hierarchical level, and can have an influence on the major decisions within the company. Over time, the "champion" becomes a "godfather", who serves as a role model for all "champions" (Lynch, 1989).

Huxham and Vangen (2005) provide two other reasons why organizations work together: a learning experience and moral imperative. There are some cases where two companies may collaborate in order to learn how to perform operations and gain experience in the field. Two companies may collaborate to learn from each other. An example is an automobile company acting as a guide or consultant to vehicle component manufacturers. This would allow for the vehicle component manufacturer to obtain a better understanding of what the automobile company expects, and for the automobile company to understand what is necessary to complete the necessary components (Huxham and Vangen, 2005). Alternatively, organizations may realize that they must work together for moral reasons to improve conditions in an industry or society (Huxham and Vangen, 2005). An example of this case is a local law enforcement agency and a federal law enforcement agency working together to carry out a plan.

If multiple organizations decide to work together, they should also be cognizant of how to maintain the relationships. Inconsistent communication can lead to dissolution of the joint venture, possibly resulting in long term negative effects for all parties involved. 


\subsubsection{Advantages of and Hindrances to Collaboration}

If collaborating organizations are able to manage the effort effectively, then all parties involved will see the benefits of the effort. Lynch (1989) enumerates the advantages of collaborating over working individually, some of which are:

- Technology transfer opportunities

- Rapid adjustment to new technological changes resulting from easier access to technological advances

- Increased operational/organizational efficiency

While there are numerous advantages from creating a joint venture, there are also factors that may impede on the development of a partnership. Huxham and Vangen (2005) outline some of the hindrances to collaborative organization:

- Organizations cannot agree on partnership terms: An example of an issue that would delay a partnership is a disagreement on the leadership structure.

- "Partnership fatigue": "Partnership fatigue" occurs when an organization is in involved in numerous partnerships and does not prefer to form any other partnerships to further deplete their resources. An example is a company that is involved in numerous partnerships and is unsure of the direct contacts in the partnering companies (Huxham and Vangen, 2005).

- Continuous changes in partnership structure, agreements, and policies: An organization may be less likely to collaborate if the partnership guidelines are not constant. Examples include individuals moving within organizations or changes in government policy (Huxham and Vangen, 2005).

In order to achieve the best possible solution for the organization, the benefits and hindrances to collaborative organizations must be addressed. If multiple organizations choose to collaborate with each other, they must be aware of all of possible hindrances, and work to avoid them. Communication throughout the process is a necessary component towards a successful collaboration. 


\subsubsection{Examples of Collaborative Strategies}

There are various ways in which organizations can work together. The components of the joint venture are dependent on factors such as the nature of the product, to what extent each party will be involved in the partnership, and how operations will be conducted during the partnership. Various authors have investigated methods as to how collaborations and joint ventures are established and managed. Some notable examples are listed in this section.

Helmut Wollmann's report "Coordination in the Intergovernmental Setting," (Peters and Pierre, 2003) describes the properties of coordination and provides examples of coordination techniques used in different countries. Wollmann indicates three types of coordination that exist today: hierarchy, network, and market. In order to include hierarchy in the intergovernmental field, the highest government level must ensure that coordinated policies are used by the lower governmental levels (Peters and Pierre, 2003). This characteristic is seen in the European government management practice called the Rechtsstaat, which uses a hierarchical organization that is essential for parliamentary democracy. Secondly, networking in intergovernmental management is described as when all parties communicate with each other voluntarily. As a result, trust and confidence are built between the parties. Examples of governments that rely on networking include Scandinavia and Germany. These governments are described as being consensus driven and rely on negotiation to solve problems. (Peters and Pierre, 2003) The final characteristic of coordination is the market, where coordination is achieved by "working behind and through selfinterest of the participants in policy making and implementation." (Peters and Pierre, 2003) However, this option is dependent on the stakeholders' willingness to share information.

Wollmann also provides two coordination methods that could prove to be instrumental in the coordination process. Decentralizing and allocating powers to lower governments transfers political roles to other elected officials. For example, the Départments in France, which are equivalent to a province or state, are comprised of regional executives with little or no power, because their power is being allocated to 
lower government levels (Peters and Pierre, 2003). Coordination can also be approached using a territory-based multi-function model, where a single unit has the responsibility of coordinating and executing tasks, or a single-function model, which is designed so that the central organization's task is to complete one specific task.

In the Beryl Radin report "The Instruments of Intergovernmental Management" (Peters and Pierre, 2003), Radin indicates that programmatic instruments are important because they provide tools intergovernmental management tools for states and local agencies. For example, the stakeholders in an interagency collaboration would ideally share their resources with the other agencies, allowing for resource pooling, joint planning and management. (Peters and Pierre, 2003) In addition, behavioral instruments of intergovernmental relations can be addressed by accounting for conflict management. If accounted for during the process, a "negotiated approach" can be taken instead of a "decide, announce, and defend approach." (Peters and Pierre, 2003) This is seen in the United States Environmental Protection Agency (U.S. EPA) as a "reg-neg" process. The "neg" (negotiation) process involves all of the affected parties in an organized debate and discussions over the proposed "regs" (regulations). Conflicts can also be addressed by using group communication. For example, a formal meeting or a town hall can be held to not only address issues, but can be used to build relationships between the stakeholders (Peters and Pierre, 2003).

Finally, Radin provides performance measures investigate the effectiveness of intergovernmental management. Radin indicates that partnerships can be ad hoc or permanent. An example of an organization that uses a "performance partnership" is the U.S. EPA, where performance criteria can be modified as necessary. A voluntary establishment of standards can be implemented as a target for the organizations to shoot for. An example of this method in use was seen in the Clinton administration, where they proposed the Voluntary National Reading and Mathematics performance standards.

In the book Organizational Design: A Step-by-Step Approach, Burton, DeSanctis, and Obel (2006) outline the steps necessary to create an organization, 
company, or partnership that will be able to function to the best of its ability. The following four steps are necessary to create an organization that will be effective for the parties involved:

- Define the goals of the organization

- Determine the organization's strategy and structure

- Identify the people that will be involved in the organization

- Determine how the organization will be coordinated and controlled.

Each step will be described below.

\subsubsection{Define the Goals of the Organization}

The first step towards creating a successful organization is to define what goals the organization will accomplish. The authors provide five questions that define the organization's fundamentals (Burton et al. 2006):

- What are the goals of the organization?

- What are the basic tasks of the organization?

- Who makes the decisions in the organization?

- What is the structure of communication in the organization?

- What is the incentive structure in the organization?

The organization's goals can also be determined in terms of its efficiency and effectiveness. "Efficiency" focuses on inputs such as resource units and costs, whereas "effectiveness" analyzes the outputs such as products (Burton et al. 2006).

\subsubsection{Define the Strategy and Structure of the Organization}

Once the organization's goals are defined, the next step is to determine the organization's strategy. Strategy is defined as the "operationalization of the firm's goals of efficiency and/or effectiveness" (Burton et al. 2006). The strategy is defined in terms of the organization's exploration and innovation abilities. Based upon these two factors, the organization can be described in four different ways, which are (Burton et al., 2006): 
- The reactor organization, which adjusts to changes after it is able to gather information from previous opportunities.

- The defender organization, which maintains the organization's current structure and strategies.

- The prospector organization, which constantly searches for new opportunities and is welcome to change.

- The analyzer organization, which maintains its current organizational characteristics while actively searching for new products and services.

The organization's environment is another important component of the organizational structure because it relates the organization to its surroundings such as the customers, competitors, suppliers, financial markets, and political systems (Burton et al. 2006). The environment is defined in terms of its complexity, which is the number of factors in an organization's environment, and interdependency and unpredictability, which is the lack of comprehension of the environment. (Burton et al. 2006). Based upon these concepts, the organization's environment can be described in the following four ways (Burton et al., 2006):

- The calm environment, where organizational conditions are simple and predictable.

- The varied environment, where the organization is dependent on political and financial issues.

- The locally stormy environment, where adjustments to solve problems can be made individually.

- The turbulent environment, where the environmental conditions are complex and unpredictable.

The organization's configuration is described as how the organization divides its large tasks into smaller tasks in terms of specialization or product. The organization's complexity specifies the organization's design in terms of the number of departments, or vertical levels within its hierarchy (Burton et al. 2006). Organizations can be described in four different ways depending on how the organization rates vertically and horizontally, which are the following (Burton et al., 2006): 
- The "blob" complexity, which involves little task specialization. However, this case does allow for flexibility and quick response to problems.

- The "tall" organization, which focuses on information processing.

- The "flat" organization, which is heavily dependent on the executive to coordinate all activities.

- The "symmetric" organization, where the middle units are responsible for coordination.

Knowledge exchange determines to what extent information technology (IT) and other technological advances are incorporated in the organization. The following four organizations describe the organization in terms of IT and other technological advances (Burton et al., 2006):

- Ad hoc organization: Information and knowledge shared on an as-needed basis. Projects originate from the individuals closest to the problem, and the organizations are dissolved after the problem is solved.

- "Informated" organization: An "informated" organization is highly involved in computer technology, and monitors customer inquiries and call center operators.

- Cellular organization: The cellular organization is defined by small groups that are self-governed and form relationships with other units within the organization as needed.

- Network communications model: This organization uses strategic alliances and partnerships to reach its goals, resulting in the creation of many connections in various directions.

The task design of the organization divides work into subtasks and addresses subtask coordination to meet the goals of an organization (Burton et al. 2006). Repetitiveness and divisibility are the two factors that are important to the task design of the organization. An organization can be defined as one of four types, depending on how it rates in terms of repetitiveness and divisibility (Burton et al., 2006):

- The orderly task design, where individuals execute work tasks independently.

- The complicated work task, where high levels of coordination are necessary due to interdependent tasks. 
- The fragmented work task, where the subunits within the organizations are independent and can work at their own pace.

- The knotty work task, which provides customer specific solutions based on nonstandardized work tasks.

\subsubsection{Identifying People Involved in the Organization}

After determining the organization's strategy and structure, the next step in the process is to determine what people will work in the organization. The best practices and strategies cannot be effectively used if the right people are not involved in the process. The type of people within the organization is dependent on the number of people and their professional abilities, and consists of the following (Burton et al., 2006):

- The "shop," which consists of people who perform simple, routine steps with a "hands on" manager.

- The "factory," where processes within the organization are simplistic and focus on efficiency.

- The "laboratory," where the workers are self driven and do not require as much supervision.

- The "office," which has many professional people who focus on efficiency and effectiveness.

\subsubsection{Determine Coordination and Control of the Organization}

Organizational activity coordination and control is the next step in the development process. Coordination and control are responsible for "linking together otherwise disparate elements of the organization structure and supporting responsiveness to changes in the environment." (Burton et al. 2006) Coordination is determined by how formalized and centralized the process is. These two concepts help to determine the following five organization types (Burton et al., 2006): 
- Family based model: This model has a few written rules and procedures. Supervision is handled by a single source. There is room for flexibility in this organization, and ad hoc coordination and control are primarily used.

- Machine model: The machine model uses documented rules and procedures, and significant attention to how work is completed.

- Market model: An emphasis is placed on more informal control sources with variations in coordination and control. The subunits primarily supervise themselves and are risk taking and innovative.

- Clan model: This group is dependent on strong leaders who formulate coordination activities by communicating extensively to employees.

- Mosaic model: The rules vary as a function of the subunit. However, there are a minimum set of standards that control the organization. These subunits engage in "dialogic democracy", which uses extensive communication across the subunits.

Control of the organization is managed by its information system. The information system is dependent on the amount of information transferred and the implied nature of the information. The four information systems based upon these factors are (Burton et al., 2006):

- The event driven system, which reacts to needs on an ad hoc basis.

- The data driven system, which distributes a high amount of information.

- The people driven system, which emphasizes face to face meetings and phone conversations.

- The relationship driven system, which integrates hard copy and computer driven data.

\subsection{Collaborative Theory in Transportation}

Collaboration in transportation is not a new concept. The transcontinental railroad is an early example of organizations working together for a common goal. The construction of the interstate highway system, which involved a funding partnership between the federal and state governments in the United States, was another 
example of a successful collaborative effort (Mertz and Ritter, 2006). The American Association for State and Highway Transportation Officials (AASHTO) is another example of a collaborative effort between the states within the United States. In recent years, coordination and collaboration between transportation organizations has become increasingly important. The federal government has introduced legislation that requires organizations such as the Metropolitan Planning Organizations (MPO) and Department of Transportation (DOT) to work together in certain activities.

\subsubsection{Common Characteristics of Collaboration}

In addition to the common characteristics of collaboration listed earlier in this chapter, transportation engineering has specific concepts that are common throughout the field, which are:

- Meetings: Most collaborative efforts involve at least one meeting between all parties involved in order to establish communication, address issues, and formulate solutions to problems. The frequency of the meetings, however, can vary depend on what the partnership addresses. An example of a meeting could be the state DOT conducting meetings with a local government or MPO to investigate solutions for a state highway corridor that runs through the local jurisdiction.

- Documented Agreements: Transportation organizations such as an MPO formulate agreements before a partnership begins. The type of agreement can vary depending on the partnership's duration and the amount of work that the collaborating organizations conduct together. An example of a documented agreement is a Memorandum of Understanding (MOU). The MOU documents what work will be completed within the partnership, the project's duration, what parties are involved in the project, and what element of the work each party will perform.

- Committees: Committees are created in order to allocate project components and discuss specific issues. In the case of collaborating transportation organizations, it is essential that committees are comprised of representatives 
from each stakeholder. An example of a committee in transportation is the Congestion Management System (CMS) committee, which solves traffic congestion issues within a specified region.

\subsubsection{Advantages and Hindrances of Collaboration}

There are advantages and hindrances to a partnership between transportation organizations. Some of the advantages of a transportation engineering partnership are:

- Increased Comprehension of Activities of all Parties: Being aware of everyone's activities can be especially important in cases where the organizations are at different hierarchical levels. An example of this situation is a state DOT collaborating with an MPO within the MPO's jurisdiction. In this case, the state DOT will benefit because they will be more aware of local issues through the MPO. Conversely, the MPO would benefit because they would be aware of where their projects are rated on the state's overall project list.

- Efficient Information Processing: Increased efficiency can be applied to fund processing, responses to questions, and project approvals. This can be achieved by streamlining processes through the joint venture, or ensuring that all parties are aware of each other's policies and processes. The project policies can be stated in a document such as the MOU.

- Meeting Federal Requirements: Establishing a transportation partnership will not only benefit the parties involved, but it will also ensure that the partnering organizations meet required governmental regulations. Federal legislation such as Title 23 of the United States code and SAFETEA-LU require that the state departments of transportation engage in collaborative activity with various transportation organizations such as the MPO or regional planning organization (RPO).

- Increase in Communication: A by-product of a collaborative partnership is increased communication. During the decision-making process, partnering organizations can communicate through face-to-face meetings, teleconferences, 
or through other media such as phone or electronic mail. Documents such as the MOU outline meeting times and provide contact information for all the involved parties.

While there are many advantages to a collaborative partnership in transportation, there can also be difficulties in the process. For example, individuals or organizations may be opposed to change if the new process is more formalized, or is significantly different from current collaborative practices. Stakeholders may have to work with individuals or different organizations that may not be familiar with current processes.

The collaborative process can prove to be effective over time. However, the partnership itself may be difficult to establish. For example, there could be issues with funding, determining the stakeholders' representatives, or creating a partnership agreement document. An example of a conflict that can occur during a collaborative effort between the state DOT and the MPO is developing a highway corridor. The MPO may prefer the corridor to be a specific length to account for local businesses, but the state DOT may want to discourage local business along the roadway to improve the corridor's efficiency. For every scenario, the goals and issues of the stakeholders should be discussed and addressed in order to achieve the most effective result.

\subsubsection{Examples of Collaborative Strategies}

\subsubsection{Funding Collaboration}

While the federal government encourages that state DOTs engage in collaboration, the actual methods that are used to collaborate vary. However, there are some collaborative methods that are common across the United States. An example of a collaborative program in the transportation field is the Surface Transportation Program (STP), which requires coordination and collaboration in terms of funding between the state and federal governments. An example of a project under the parameters of the STP could involve the coordination of a bicycle path or lane that 
crosses into other jurisdictions. The STP serves as one of the major sources of funding from the Federal Government for construction projects performed by the state DOTs. Originally created under ISTEA in 1991 and further modified under TEA-21 in 1998, the STP provides funding for various types of projects. Some of the projects that may use STP funding are:

- Construction and reconstruction on highways and bridges.

- Capital costs for specified transit projects listed under Chapter 53 of the United States Title Code.

- Carpool projects

- Corridor parking facilities

- Bicycle transport

- Pedestrian walkways

- Highway and transit safety improvements

- Transportation enhancement activities

These projects and others are listed under Title 23 of the United States Code, which describes the conditions for STP funding in detail. For projects that meet STP requirements, the funding source is divided into three major categories. Twenty five percent is based upon total lane miles of federal aid highways, 40 percent is distributed according to total vehicle miles traveled on Federal Aid Highways as a percentage of total Vehicle Miles Traveled in each state, and 35 percent is provided from estimated tax payments. Currently, the STP is a component of the Safe, Accountable, Flexible, and Efficient Transportation Equity Act: A Legacy for Users (SAFETEA-LU), with the only notable difference being that safety has been separated from the STP into its own entity. Despite further additional improvements due to new legislation, the STP continues to be one of the more successful funding distribution programs today.

\subsubsection{Transportation Planning Collaboration Examples}

Another example of collaboration in transportation is the Unified Planning Work Program (UPWP), which coordinates transportation and comprehensive planning. Project funding is provided jointly by federal, state, and local governments. The federal 
government provides 80 percent of the funding while the remaining 20 percent is provided by the state and local governments. In the case of the Baltimore Regional Transportation Board (BRTB), which is responsible for the " $3-\mathrm{C}$ (continuing, cooperative, comprehensive) planning process," the BRTB membership is comprised of five county representatives, three state department representatives (transportation, environment, and planning), and the Maryland Department of Transportation (MDOT) (Baltimore Metropolitan Council [BMC], 2006). Under the UPWP, BRTB organizes the long term transportation plans in the Baltimore metropolitan area, including intermodal and system access planning, and air quality and other environmental standards.

The congestion management system (CMS) is another example of transportation collaboration. Some MPOs may choose to form a standing committee whose goal is determine solutions for transportation congestion issues within the jurisdiction of the MPO. An example of an effective CMS subcommittee is the Wilmington Area Planning Council (WILMAPCO), which includes representatives from MDOT, the Delaware Department of Transportation (DDOT), the city of Wilmington, Delaware, and county officials from Delaware and Maryland. The WILMAPCO CMS subcommittee uses a set of procedures to identify and address congestion issues within the study area. The steps are (WILMAPCO, 2005):

- Review annual performance measure data.

- Identify congested corridors by consensus.

- Develop a matrix of possible congestion mitigation solutions.

- Monitor changing traffic conditions and trends.

WILMAPCO also uses other performance tools to identify problematic areas such as travel time data, traffic time, and public transit performance.

While there are examples of coordination and collaboration in transportation, the structure and management of these organizations varies. Communication and a written agreement between the parties are requirements for a successful partnership. However, there is no standard for how transportation partnerships are created and managed. In this study, partnership structures will be formulated and suggestions as to how to create partnerships will be made. 


\section{CHAPTER 3. RESEARCH METHODOLOGY}

\subsection{Introduction}

A literature review is just one of the components needed to identify effective collaborative strategies between transportation organizations. A systematic process was developed to investigate the issues, requirements, possible examples, and solutions of collaboration and coordination between transportation organizations. The research methodology consisted of the following steps:

- Legislation research

- Case study review

- Search for transportation collaboration examples

- Search for collaborative efforts in other disciplines

- Survey study

The findings for each step are described later in the chapter.

This study is focused on multi-jurisdictional issues related to congestion management. The findings from this research will serve as a foundation for the collaborative strategies suggested presented in the next chapter.

The organizations involved in a multi-jurisdictional project can vary, depending on the project. INDOT and MPOs can be involved in collaborative strategies. Collaborative efforts can occur between organizations on the same hierarchy level, such as MPO-MPO, or on varying hierarchy levels such, as county-city.

\subsection{Legislation Research}

The first step towards suggesting collaborative strategies was to review the Federal legislation that required collaboration between state and local agencies. The necessary legislative documents were obtained from the Federal Highway Administration (FHWA) website, and were reviewed for relevance to this project. Four legislative documents were reviewed: Intermodal Surface Transportation Efficiency 
Act (ISTEA), the Transportation Equity Act for the $21^{\text {st }}$ Century (TEA-21), the Safe, Accountable Flexible, Efficient Transportation Equity Act: A Legacy for Users (SAFETEA-LU), and Title 23 of the United States Code.

Title 23 of the United States Code serves as the main reference for transportation planning, and ISTEA, TEA-21, and SAFETEA-LU provide amendments. In terms of collaboration and coordination between the state DOT and MPO, Sections 134 and 135 provide basic guidelines for coordination. Section 134, Part A indicates that the MPO will develop transportation plans and programs in conjunction with the state and public transit organizations. Coordination regulations are also described in Part D of Title 23, which indicates that the Secretary of Transportation will encourage governors with partial responsibility for metropolitan areas to collaborate with the MPO on the entire transportation plan for that area. Furthermore, Section 135, which outlines statewide planning, indicates that the state will coordinate with the MPO on the state implementation plan. The state will also coordinate with the MPO on documents such as the Long Range Transportation Plan (LRTP) and the Surface Transportation Improvement Program (STIP) under the conditions of Section 134 of this code $\left(105^{\text {th }}\right.$ Congress, 1999).

In Part D of Section 1024 of ISTEA, the legislation indicates that the Secretary of Transportation will encourage state Governors and MPOs to provide a coordinated transportation plan for the urban area. Part E of ISTEA also indicates that MPOs will collaborate on projects pertaining to the Clean Air Act (CAA). Part $\mathrm{H}$ indicates that the state will coordinate with transit agencies and MPOs towards the development of the Transportation Improvement Program (TIP) (102 ${ }^{\text {nd }}$ Congress, 1991). Section 1034 provides an Amendment to Title 23, indicating in Section 303 that management systems involving federally funded highways and bridges, highway safety, traffic congestion, public transportation, and intermodal facilities shall be developed jointly with the MPOs $\left(102^{\text {nd }}\right.$ Congress, 1991). From the state perspective, Part B of Section 1035 indicates that the State will coordinate its activities under the requirements of Section 134 of Title 23 (102 ${ }^{\text {nd }}$ Congress, 1991). 
TEA-21, introduced in 1998, served as an improvement to ISTEA, and expands coordination efforts between the state department of transportation (DOT) and the MPO. Sections 1107 and 1115 describe collaboration and coordination. Section 1107 provides an amendment to Section 119 of Title 23, indicating that the Secretary of Transportation will collaborate with the state and MPOs to determine the current condition of the interstate system and decide what improvements are necessary $\left(105^{\text {th }}\right.$ Congress, 1998). Section 1115 provides an amendment to Section 204 of Title 23, indicating that "regionally significant" federal land projects will be coordinated with the state and MPOs, and included in the local, state, and federal TIPs. Section 1118 provides amendments to Section 101 of Title 23, indicating that corridor planning will be coordinated with state and local plans in the area. Finally, Section 1203 indicates that the Secretary of Transportation will encourage Governors who each have responsibility for a portion of a multi-state metropolitan area to develop a transportation plan for the entire multi-state metropolitan area.. This section serves as an amendment to Section 134 of Title $23\left(105^{\text {th }}\right.$ Congress, 1998).

SAFETEA-LU expands upon collaborative standards established by ISTEA and TEA-21. As of November 2007, SAFETEA-LU is the current transportation legislation. Section 3005, Subsection 5303, Part G indicates that the Secretary of Transportation encourages the MPOs to coordinate their activities with other transportation officials within the state. Moreover, Section 3005, Subsection 5304 indicates that the state will coordinate their metropolitan planning activities and multistate efforts, if necessary. Section 3006, Subsection 5304 also provides regulations for coordination between the state and the MPO. Part F indicates that the state will develop its statewide transportation plan with both metropolitan and non-metropolitan areas (109 ${ }^{\text {th }}$ Congress, 2005).

These four documents provide a starting point for collaboration between the state DOT and the MPOs. However, the legislation does not indicate a process that should be used to coordinate activities. As a result, the study included a literature search and survey to determine the collaborative efforts that would best fit these two agencies. 


\subsection{The Ronald Reagan Corridor Master Plan}

The Ronald Reagan Corridor is a 12-mile segment of roadway connecting Interstates 70 and 74 . The master plan is instructive because it requires a coordinated effort between governmental agencies along the corridor. Specifically, the master plan is a joint product of Hendricks County, and the Indiana towns of Avon, Brownsburg, and Plainfield. A map of the project corridor is provided in Figure 3.1.

Before creating the corridor master plan, representatives from each of the agencies involved created a set of goals that the project would accomplish (HNTB and Hendricks County, 2005):

- Inter-Governmental Cooperation

- Create a Land Use plan that establishes the parkway as an economic corridor.

- Design the corridor to be aesthetically pleasing.

- Create an access management plan that allows for efficient travel along the corridor.

- Promote non-motorized transportation modes along the corridor.

- Preservation of Unique Features

The goals that are most relevant to the Multi-Jurisdictional Issues Relating to Congestion Management study are inter-governmental cooperation and access management. The corridor study indicates that inter-governmental cooperation is the most significant goal of the corridor project. The involved agencies should adopt the corridor master plan to ensure the project's success (HNTB and Hendricks County, 2005). Access management is also relevant to the Multi-Jurisdictional study because the various organizations must work together to control intersection, driveway, and signal spacing along the corridor (HNTB and Hendricks County, 2005).

HNTB and Hendricks County (2005) illustrate the need for the four jurisdictions to work together. Before the Ronald Reagan Corridor Master Plan was developed, all of the jurisdictions except for Plainfield developed their comprehensive Land Use plans. When comparing the four master plans, however, there are several conflict points (HNTB and Hendricks County, 2005). For example, the Hendricks County plan focuses more on Commercial and Industrial use along the corridor, whereas the town 


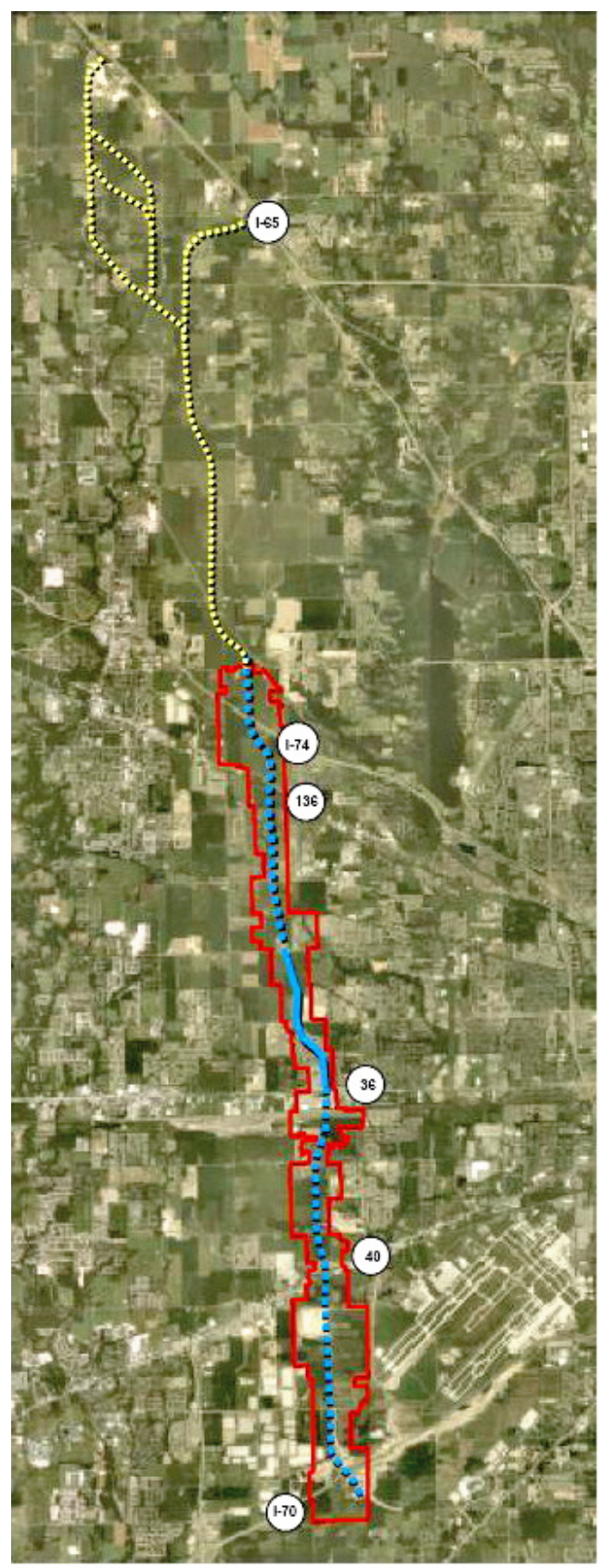

STUDY AREA BOUNDARY

RONALD REAGAN PARKWAY -BUILT

- RONALD REAGAN PARKWAY -PLANNED

POTENTIAL FUTURE ALIGNMENT

OPTIONS FOR EXTENSION TO I-65

Figure 3.1 Ronald Reagan Corridor Map (HNTB and Hendricks County, 2005) 
plans are more divers in land use functions, such as residential and office uses (HNTB and Hendricks County, 2005). There are also two major areas of conflict between Avon and Hendricks County, and between Avon and Plainfield. In the first case, Avon designates the land between U.S. Route 40 and Morris Street as residential, conflicting with the county's commercial and industrial designation. The second case, which is also located along U.S. Route 40, has Avon using the land for residential purposes and Plainfield assigning a commercial designation to the land (HNTB and Hendricks County, 2005). The two land use plan conflict areas are shown in Figure 3.2.
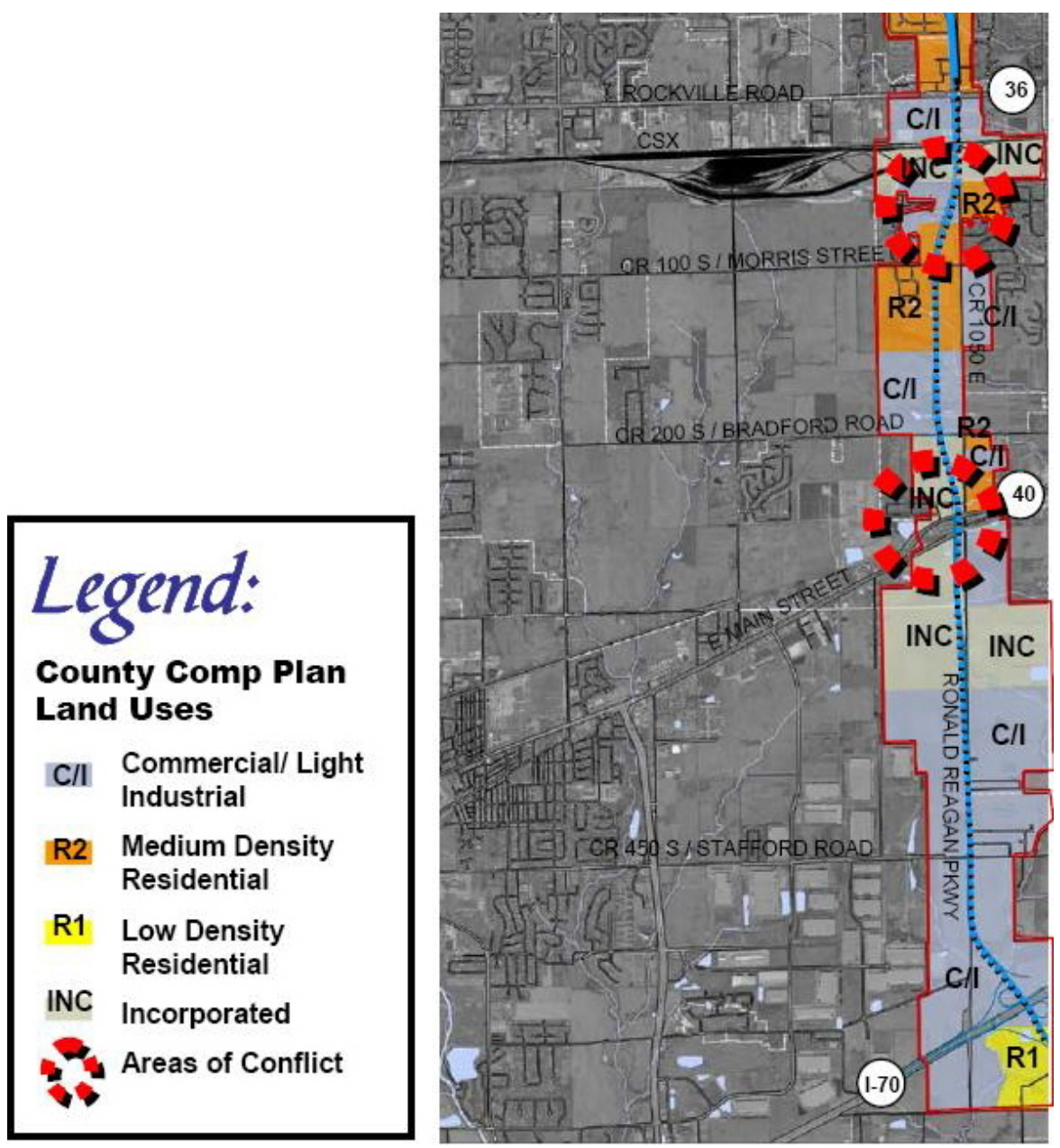

Figure 3.2 Land Use Plan Conflict Areas (HNTB and Hendricks County, 2005) 
The recommended land use plan attempted to use elements from the four previous plans. The meetings and discussions led to a final plan, in which a consensus on a land use patterns for the corridor was reached.

\subsection{Transportation Collaboration Examples}

A search for examples of collaboration within the transportation field was undertaken. The literature search examined documents from all three levels (federal, state, and local) to identify strategies and examples of collaboration in the transportation field.

\subsubsection{Consensus Decision-Making Process}

Some transportation organizations use a consensus decision-making process to determine solutions to problems. The consensus process is effective because it allows for the individuals involved in the decision-making process to voice their opinions on an issue (Alberta Public Interest Research Group [APIRG], 2005). Various sources such as Kerrigan (2004), The Common Place (2005), and the APIRG (2005) have described the steps which take place in the consensus decision-making process, which are:

- Hold an open discussion to introduce and clarify the topic or issue to the stakeholders.

- Discuss possible solutions, and its advantages and hindrances through brainstorming and ensure that each stakeholder is aware of the proposed solutions.

- Call for a consensus between the stakeholders. If a consensus cannot be reached, the organization would repeat the previous two steps to address the disputed issues.

In the event that a consensus can not be reached, the stakeholders in the organization have the option of standing aside to allow for solution approval, breaking down the issue into smaller components for further investigation in smaller groups, or concluding that a solution can not be reached (Kerrigan, 2004). Examples of 
transportation organizations that use consensus decision-making processes are discussed in Section 3.4.2.

\subsubsection{Transportation Collaboration in Other States}

There were three documents that provided examples and ideas of collaborative efforts within the transportation field. The first, called Transportation Collaboration in the States, involved the National Policy Consensus Center (NPCC) researching collaborative practices used throughout the country. In particular, the study focused on four states: Utah, Massachusetts, North Carolina, and Virginia. Representatives from each of the four states were interviewed and a set of assessment criteria were used: feasibility of access to state decision-makers, experience level and interested in collaborative projects, state involvement in planning and the National Environmental Policy Act (NEPA), and if there are opportunities to advance in collaborative activities (NPCC, 2006). The study was conducted through site visits and interviews with officials in the four states.

The results of the study indicated some common problems with collaboration in all of the states. The NPCC identified issues with coordination between the state and the MPOs, issues with the development of collaborative systems, and issues with political influence on transportation activities. The study also indicated some of the collaborative practices currently in use by each of the four states, which are described below. It should be noted that the NPCC survey results provided other examples of collaboration and suggestions for future work in the field. However, only the examples most relevant to the study are presented.

\subsubsection{Collaboration in Utah}

The State of Utah uses an interagency executive committee, consisting of administrators from the transportation planning and resources agencies. The executive committee is responsible for policy improvement (NPCC, 2006). The FHWA 
played a key role in Utah by establishing and participating in the executive committee. Other areas of collaboration include multi-modal transportation modeling, environmental and land use planning, and construction.

\subsubsection{Collaboration in Massachusetts}

In Massachusetts, the Highway Department collaborated with advocacy organizations, regional and professional organizations, and other stakeholders to rewrite the Massachusetts Highway Design Manual. The organizations formed a task group, which was supervised by an individual independent of the collaborative organizations. A neutral facilitator was also used to assist the governmental organizations through the restructuring of the Boston MPO.

\subsubsection{Collaboration in North Carolina}

In North Carolina, public agencies have collaborated to form the North Carolina Interagency Leadership Team (NCILT), which consists of the following members:

- North Carolina Department of Transportation (NCDOT)

- North Carolina Department of Environmental and Natural Resources

- North Carolina Department of Cultural Resources

- North Carolina Wildlife Commission

- United States Army Corp of Engineers

- FHWA

- United States Fish and Wildlife Service

- United States Environmental Protection Agency (U.S. EPA)

- National Marine Fisheries Service

All of the involved agencies believe that collaboration is necessary for the benefit of the entire state (NPCC, 2006). The NCILT uses a consensus driven process, ensuring that issues are addressed for the benefit of all stakeholders. The NCILT works on projects such as the Long Range Transportation Plan (LRTP) and Land Use Plan. Other areas of collaboration in North Carolina include the FHWA and NCDOT working with the MPOs and regional planning organizations (RPOs) to redevelop the long 
range process and the Triangle Mobility Forum Action Partnership, which is a discussion forum involving:

- MPOs

- County Representatives

- City Representatives

- Legislators focused on transportation issues

- Other stakeholders

Similar to the NCILT, this organization is built upon a consensus driven process.

\subsubsection{Collaboration in Virginia}

The commonwealth of Virginia uses media such as websites and newsletters to inform the public on progress in the transportation process (NPCC, 2006). Virginia has also used facilitation on other transportation projects. For example, the Virginia Department of Transportation (VDOT) formed and oversaw the Bryan Park Interchange Advisory Committee (BPIAC), comprised of local citizens, whose mission was to provide ideas and suggestions to address congestion issues at the interchange connecting Interstates 64,95 , and 195 , while protecting the park and community that was located nearby (BPIAC, 1999). The Bryan Park Interchange Advisory Committee used a consensus driven decision-making process.

\subsubsection{Common Collaborative Themes from NPCC}

The NPCC also discussed common collaborative hindrances discussed by the four states, and provides suggestions for improving them (NPCC, 2006):

- Land-Use Transportation Coordination: According to the NPCC, only a few states use an integrated approach to address land use and transportation coordination. Methods to solve this problem include educating transportation officials and other stakeholders about coordination, developing a consensus driven collaborative process, and using computer software to incorporate transportation, land use, and the economy (NPCC, 2006). 
- Collaboration between Local Agencies, MPOs, State and Federal Organizations: Issues with collaboration and coordination can result from land use and transportation coordination and the lack of opportunities for local organizations to have a voice in collaborative projects. The NPCC suggests that earlier project coordination and hosting discussion forums including local agencies can enhance the collaborative process (NPCC, 2006).

- Early Involvement of Environmental and other Resource Organizations in the Transportation Planning Process: The four states also indicated that the environmental and other resource organizations do not "have a seat at the table"' (NPCC, 2006). To alleviate this problem, the NPCC suggested that incorporation of coordination strategies and dispute resolution methods into the planning process.

- Modal Coordination/Multi-Modal Planning: Disputes can result from issues with coordinating the five main transportation modes (highway, rail, transit, aviation, and seaports) because they are planned by different agencies. The NPCC indicated a need for collaborative strategies between transportation agencies and other stakeholders in areas such as aviation, public transportation, and railways.

The NPCC noted areas where there are examples of effective collaborative strategies. These include the political leadership role in planning and the continued development of the collaborative process. For example, the NCILT was created with the encouragement of the Governor of North Carolina and organizations such as the Executive Committee in Utah developing collaborative strategies (NPCC, 2006).

\subsubsection{Collaboration in Kentucky}

The Kentucky Transportation Cabinet (KYTC), the state DOT in Kentucky, is developing a transportation manual that will include collaborative strategies for the state DOT and other transportation agencies. Work Element Nine of this manual outlines "points of coordination", which are: 
- Plans and programs of state, local, MPOs, Area Development District (ADD), public transportation organizations, intermodal facilities such as airports, and private agencies.

- Land use plans

- Emergency response and various health services

- Environmental planning and management

Once the manual is completed, the transportation plans will be collected in a file, which will be made available to other organizations as needed (KYTC, 2007).

\subsubsection{Collaboration in Indiana}

Currently in Indiana, the most tangible example of collaborative efforts between transportation agencies is contained in the Indiana MPO Council Handbook. This handbook provides guidelines for transportation planning and basic requirements for collaboration with the state DOT and other agencies. Within this document are two distinct sections that provide coordination guidelines between the state DOT and the MPOs. Section 2.2 of the document describes the Memorandum of Understanding (MOU), which outlines the work that will be done, the organizations that will be involved, the extent to which the organizations will be involved, and other issues such as funding and dispute resolution. Specifically in Section 2.2.2., the MPO is responsible for writing and editing the MOU and the INDOT Programming Section Manager coordinates the INDOT approval process (Indiana MPO Council, 2007). Section 4.2 describes a Project Coordination Team designed to improve coordination between the transportation planning agencies, such as the state DOT and the MPO. The Project Coordination team is not clearly defined in the handbook and is only discussed during coordination of environmentally related projects such as an Environmental Impact Statement.

\subsubsection{Collaboration in Congestion Management}

In addition to researching collaborative partnerships between the state DOTs and MPOs, collaboration between jurisdictions concerning congestion management 
issues was also addressed. The article "Building Congestion Partnerships to Support the Vital Few" (FHWA, 2006) analyzes what components are necessary for a congestion management partnership, which is defined as an "ad hoc, informal, or institutionalized" collaborative effort between transportation network public and private stakeholders. Some of the organizations that can be involved in a congestion management partnership include highway agencies, law enforcement agencies, governmental agencies, transit agencies, and emergency agencies. The report also indicates that the partnership usually involves regular meetings to address regional network operations, determine methods of minimizing congestion, and serve as an opportunity to share information between the involved parties (FHWA, 2006).

Not only did the report describe characteristics of the congestion management partnership, it also provided examples of organizations that use congestion mitigation partnerships in their daily activities. The first example, AZTech, is comprised of stakeholders from various agencies who meet to discuss issues such as traffic signal coordination, evacuation plans, and the integration of local and state traffic operation centers (FHWA, 2006). Organizations involved in AZTech include the Maricopa County Department of Transportation, the Arizona Department of Transportation, MPOs, emergency management, and the Sherriff's Department.

A second organization that uses a congestion management process is the Wastach Front Regional Council (WFRC). The agency, which is responsible for five counties in Utah, consists of representatives from the Utah Association of Cities and Towns, the Utah Association of Counties, and city officials. The WFRC encourages the Utah MPOs to collaborate with county and state officials on congestion management strategies such as access management to ensure that the best solution strategies are discussed and implemented (WFRC, 2006). Collaboration is also encouraged to improve public transit agencies.

Another example of an organization that effectively collaborates on congestion management issues is the Wilmington Area Planning Council (WILMAPCO). This MPO covers areas within the states of Maryland and Delaware. WILMAPCO involves the state DOTs of Maryland and Delaware, county representatives, the city of 
Wilmington, Delaware representatives, and other city and transportation planners. Another unique characteristic of WILMAPCO is that it designates a Congestion Management System subcommittee within the organization, dedicated towards solving congestion management issues within the metropolitan area. The specifics of the congestion management subcommittee will be discussed in the next chapter as a case study.

The Baltimore Metropolitan Council (BMC) is an example of another organization that uses a congestion management system to address congestion issues in the metropolitan area. In this case, issues with congestion management are addressed as they arise. According to the Baltimore Metropolitan Council website, congestion management issues are addressed by the Baltimore Regional Transportation Board as necessary throughout the course of a project (BMC, 2006b). Other coordinated activities include emergency coordination and traffic operations (BMC, 2006c).

\subsection{Collaborative Efforts in Other Disciplines, Part One}

Federal legislation requires that transportation organizations collaborate and coordinate their activities, but does not indicate how they should be formed and managed. Collaborative strategies used in one state may not be applicable in another due to factors such as governmental and organizational structure and funding. As a result, the literature search was extended to other fields inside and outside of transportation planning. Some of the fields investigated included economics, management, social sciences, and other engineering disciplines. In the economics and management fields, many organizations have been established to efficiently manage new products and their finances. Books such as Organizational Design: A Step-by-Step Approach (Burton et al., 2006) and The Practical Guide to Joint Ventures and Corporate Alliances (Lynch, 1989) and other documents have been created that outline the structure of an organization and provide suggestions as to how to form successful joint efforts. 
The Social Sciences field also provided examples of collaborative guidelines and collaborative efforts within an organization. Many of the references focused on intergovernmental management, which is an agreement between two governmental agencies to work together for specific projects. Other references focused on collaborating in organizations without having a traditional hierarchical structure. The alternate collaborative structures will be discussed and analyzed in the next chapter.

Collaboration has occurred in some form in all engineering fields. However, the search for collaborative efforts focused on construction management, because collaboration between the owner and contractors is the key component of completing a project. For example, a study was performed by the Collaborative Process Institute (CPI) to determine if the Acton Peninsula Project Alliance (APPA), which was responsible for the construction of the National Museum of Australia, was effective in using collaborative strategies. Some of the positive features of the alliance included common office space, high levels of cooperation, and complex problems being solved at the lower levels. In order to determine who would be involved in the alliance, the leaders used a series of qualifying criteria (Hauck et. al 2004):

- Demonstrated ability to complete the full scope of work

- Demonstrated ability to minimize project capital and operating costs without sacrificing quality (value analysis and lifecycle costing)

- Demonstrated ability to achieve outstanding quality results

- Demonstrated ability to provide the necessary resources for the project and meet the project program (Including resumes of key staff)

- Demonstrated ability to add value and bring innovation to the project

- Demonstrated ability to achieve outstanding safety performance

- Demonstrated ability to achieve outstanding workplace relations

- Successful public relations and industry recognition

- Demonstrated practical experience and philosophical approach in the areas of developing sustainability and environmental management

In addition, the APPA created a set of communication standards that would be used for the duration of the project. Communication was based on the principles of 
equality, openness, problem orientation, positive intent, empathy, and technology use. The APPA also used meetings effectively and had professional facilitation for all meetings. There were high levels of informal correspondence, and the organizations shared a database of documents that were pertinent to the project. The APPA utilized the ProjectWeb coordination software, which used common communication forms that were collected in one location. The software also allowed for e-mails and document uploading. Finally, the APPA's problem solving techniques relied on the project alliancing concept; project alliances force collaboration to achieve the best project outcome by all parties (Hauck et. al 2004).

Another concept drawn from the construction management field is how to solve disputes between parties. The book titled Disputes and International Projects by David G. Carmichael (2002) was reviewed to find methods of how to avoid disagreements between committee members, and determine methods of solving disputes, if they arise. Specifically, Carmichael focuses on construction project relationships, such as owner with contractor and contractor with sub-contractor. Carmichael uses case studies to discuss various points at which disputes typically arise. Carmichael concludes his book with a discussion of various dispute resolution methods using case studies that further reinforce the discussed topics.

A topic discussed in Carmichael's book that is relevant to this research project is his discussion of formal cooperation. Carmichael indicates that there are two major types of formal cooperation: alliances and partnerships. There are two types of alliances. The strategic alliance involves collaborative efforts between two or more groups over an extended period of time, whereas the project alliance involves a collaborative effort among two or more organizations throughout the duration of a construction project. Carmichael specifically indicates that a formal contract does not have to exist between the parties, and parties can use any supplier they prefer (Carmichael, 2002). In contrast, the project alliance is more formalized but still does not require a specific contract outlining the agreement. The project alliance is formed simultaneously with the contracts necessary to complete a construction project. In project alliances, parties share the work, liability, and responsibilities. Unlike an alliance, the partnership is a completely formal cooperation method. Carmichael states 
that the purposes of the partnership can be achieved through an alliance, but the partnership is still used on a case by case basis (Carmichael, 2002). The features of a partnership that could pertain to this study are (Carmichael, 2002):

- A mission statement describing project goals, business goals, and dispute resolution methods. The mission statement is agreed upon by all parties included in the partnership.

- A definitive time limit for solving disputes

- Training for project personnel to ensure cooperation during the project

- Regularly scheduled meetings and continuous communication between parties

In addition, Carmichael analyzes the benefits and hindrances of partnerships. Some of the benefits include reduced time for preparation of contracts, decreased administrative costs, and the possibility of better communication between involved members. Partnership hindrances include increased initial costs from staff and management, and ineffective results when the two parties do not have equal power (example: contractor and sub-contractor).

Carmichael introduces various case studies to illustrate the characteristics of the two types of collaboration. The first case study involved a partnership between a rail company and a railroad signal contractor to update the rail company's railroad signals. The plan was to combine the two entities' efforts to ensure that the project was completed efficiently. However, the partnership ended prematurely when the contractor underestimated the size of the project close to scheduled completion. The second case study was an interview with a project engineer about projects that they have worked on. The relationships were described as being "best friends to worst enemies," indicating that partnerships may not be effective in all projects. A third case study involved a partnership between miners, maintenance providers, and an equipment manufacturer. In this case, the author indicates that the lack of commitment from higher. As a result, the benefits of partnership were not seen. Based upon the results of the case studies, if higher management is involved and committed to the partnerships, ways of solving disputes are included in the agreement, and if the final goals are edited as the partnership progresses, then cooperation between parties will have the best results. 
Carmichael also describes different ways of solving disputes. The following seven methods were discussed:

- Negotiation, which involves each party trying to get the other parties to see their point of view.

- Mediation, which has the same characteristics of negotiation, but also involves a third party. However, the two parties are left to decide a solution once mediation is complete.

- Conciliation, which is similar to mediation with the exception of the third party providing their opinion on the dispute throughout the discussion.

- Expert appraisal, where it is similar to mediation except that this option is typically used for technical disputes. In this process, the mediator has knowledge of the technical aspects of the dispute and provides a decision in writing after both parties explain their sides of the story.

- Expert determination, which is similar to expert appraisal except that the moderator's decision is final.

- Senior executive appraisal, where an administrator representing each party is assigned to lead negotiations. A mediator is present throughout this meeting.

- A disputes review board, which involves a board of officials agreed upon by both parties, is assigned to make the final decision. In this process, the two parties present their cases, and a neutral party can be introduced to mediate throughout the process.

The construction management field also provided guidelines for meetings in the collaborative process. Ulla Merz's report "Project Meetings: a Communication and Coordination Tool" (Tinnirello, 2002) analyzes the concept of the meeting and provides suggestions on how to make it a more successful tool within an organization. Merz identifies the common features of meetings such as addressing issues of concern, making everyone aware of changes, ensuring that everyone gets the same information and limitations to face-to-face time (Tinnirello, 2002). Merz also indicates some of the characteristics of effective meetings. The meetings should meet the 
needs of each participant; concerns important to the group are addressed, identify a clear purpose, and be conducted in a comfortable atmosphere (Tinnirello, 2002).

In order to make meetings effective, the meeting's purpose must be identified, a clear agenda must be written, the work products resulting from the meetings should be identified, and must create an atmosphere for success. There are three basic formats: exchanging information, making decisions, and problem solving. The information exchange meeting raises technical issues and announces member changes. The information exchange meeting serves as a good forum for members to discuss ideas with other members. The decision-making meeting provides participants with facts necessary to make decisions. The problem solving meeting formulates a common problem definition. The agenda is an outline of the meeting's content. The meeting minutes should use a standardized template to ensure faster processing of information (Tinnirello, 2002).

Merz also provides suggestions of improving a meeting's atmosphere. The meetings should use a common format; the facilitator should provide guidance and allow for open discussion for the meeting. Communication should be based upon trust with all parties. To use the meeting as a coordination tool, all members should be informed of all actions pertaining to the meeting; it should provide opportunities for contributions of expertise and knowledge. Finally, the meeting's goal should be to achieve agreement and support of the outcome by all parties is essential (Tinnirello, 2002).

\subsection{Survey Development}

In addition to a literature search, a survey was created to obtain the opinion of transportation officials who would be directly affected by changes in collaborative strategies and to ensure that the practical perspective of collaboration in transportation was maintained. The questions developed in the survey were based upon the preliminary results from the literature search and conversations with transportation professionals. The survey was distributed to the six INDOT districts and to selected 
states. The survey was used to collect imformation for two studies. Those questions that pertain to this study are shown below.

1. (For other study)

2. (For other study)

3. (For other study)

4. (For other study)

5. Would a written set of guidelines help or hurt the coordination process?

6. Should meetings between representatives of organizations concerned with transportation planning be held on a regular basis? If so, how often?

7. (For other study)

The responses to the questions varied; however, there were some common themes evident. The survey was also compared to the KYTC transportation manual, which as of November, 2007, is still in the development stages. A summary of the common themes is described in this section.

The responses from the INDOT districts indicate that collaboration varies from district to district. For example, in one district, the MPOs are involved in an annual meeting to discuss transportation planning documents and strategies. However, it has been noted that the interests of the state sometime conflict with the MPO districts, as the MPO's focus is much more localized than the state. However, regularly scheduled meetings to discuss issues were also described in the surveys distributed to other states, although the degree of collaboration varied.

The responses from the INDOT districts and the states indicate that local public agencies are important in the collaborative process, and that public involvement also has a significant role. However, one state indicated that intermodal and freight organizations should also be involved in the process.

When asked to describe other issues that a collaborative effort could address, every response with the exception of one district indicated that most of the common issues are currently addressed in existing documents. All of the responders with the 
exception of one state indicated that a set of written guidelines would help the communication process. However, the guidelines should not hamper current collaborative efforts between organizations or make planning procedures more confusing. Only one survey responder indicated that written guidelines would hurt the communication process, because they might conflict with the collaborative efforts already in place.

The officials from the three surveyed states and two INDOT districts indicated that regularly scheduled meetings with organizations such as INDOT or MPOs should be held to address issues so that feedback, discussion and issue resolution could take place. The suggested frequency of the meetings varied from one per month to one per year. In addition, two of the states indicated that meeting flexibility is necessary, in particular for the MPOs. Regularly scheduled meetings are commonplace among transportation agencies, as indicated by the Indiana MPO Handbook, Section Two of the KIPDA MOU, and the KYTC Planner's Manual. For example, the KYTC meets bimonthly for Statewide Transportation Planning meetings, but the meeting attendees are not specified in the Planner's Manual.

\subsection{Collaborative Efforts in Other Disciplines, Part Two}

Another literature search was conducted to determine additional collaborative structures and management tools, using the same fields as the first literature search. The results from this literature search will be used in conjunction with the research conducted before to suggest collaborative strategies in Chapter Four.

The results of this literature search indicated an organizational concept that can be used for management. The Richard Elmore report "Backward Mapping: Implementation Research and Policy Decisions" (Williams et al., 1982) investigates an alternate method of implementation strategies known as backward mapping. Backward mapping is a problem solving technique that originates from the perspective of the individuals or groups that are closest to the problem. It provides an opportunity for specific individuals or groups to contribute directly to the decision-making process, 
where they may not have an opportunity to voice their opinion during the decisionmaking process using the forward mapping approach. However, the organization's administrators remain the final decision-makers, because they review the solutions developed by the various departments or sections, and determine which strategies will benefit the organization. Elmore also investigates forward mapping and points out the drawbacks of the process.

Elmore describes forward mapping as a top to bottom process. The process begins with a clear statement of the policymaker's intent. A sequence of specific steps is followed down the hierarchy using to define the organization's expectations. At the bottom of the process, a satisfactory outcome is defined as having a clear mission statement for the organization's plan (Williams et al., 1982). An example of a forward mapping process is federal policy, which uses a statement of congressional intent to define its overall goal. Responsibilities are then divided so that each unit has a clearly defined mission. Once missions are defined, the final outcome is clearly explained (Williams et al., 1982). Elmore states, however, that one of the weaknesses of forward mapping is that it uses the assumption that "policymakers control the organizational, political, and technological processes that affect implementation" (Williams et al., 1982). A typical organization consists of other individuals who are responsible for executing policies developed by administrators.

The backward mapping logic starts at the point in the decision-making process where administrative actions overlap individual decisions. Similarly to forward mapping an objective is stated in terms of operations and outcomes. The analysis then proceeds backwards through the hierarchical structure of the implementing agency asking the following questions (Williams et al., 1982):

- What is the ability of this unit to affect the behavior that is the target of this policy?

- What resources does the unit require in order to have an effect? Policymakers then describe a policy that directs resources at the organizational units most likely to have the greatest impact. Backward mapping is dependent upon assumption that the analytic solution stresses dispersal of control and concentrates on factors that can only be influenced by policymakers (Williams et al., 1982). 
As stated previously, the analytical solution to backward mapping stresses dispersal of control and concentrates on factors that can only be influenced by policymakers. While the formal authority still travels from top to bottom, the informal authority comes from the stakeholders who have the experience necessary to complete the process. Backward mapping is defined as "a formal authority dependent on specialized problem solving capabilities farther down the chain of authority" (Williams et. al, 1982).

A second management model that could be used to help a collaborative effort is the jurisdiction-based model for intergovernmental management. The jurisdictionbased model is dependent upon three intergovernmental management characteristics: interdependence, strategic activity, and multiple actors. This model typically occurs under uncertain complex conditions where projects cannot succeed without collaboration.

In the report "A Jurisdiction-Based Model of Intergovernmental Management in U.S. Cities", Agranoff and McGuire (1998) created variables that would determine the operations of the jurisdiction-based model. The dependent factor was determined to be policy activity from the vertical environment, where an administrator makes decisions and the plan is executed along the hierarchical level, and the horizontal environment, where the individuals make a consensus based decision. These intergovernmental management factors were developed from survey questions asking about both intergovernmental and inter-local characteristics. The explanatory variables were also determined from surveys of government officials, and were determined to be the following (Agranoff and McGuire, 1998):

- Bargaining behavior: The extent of city managers' collaboration and negotiation with state and federal governments.

- Formal adjustment behavior: The degree that managers seek discretion from grating or regulating governments.

- Strategic activity: How much the city strategically targets federal interaction

- Internal barriers: A measurement of the perception of intergovernmental management barriers. 
- "Intersectoral" policy leadership: The amount of sectors that are involved in the policymaking and administration processes.

- Importance of state government: The city officials' impression on the significance of the state government in collaborative strategies.

- Contact with other cities: The degree of collaboration with other cities.

These concepts will be used to create collaborative examples in the next chapter.

\section{8. $\underline{\text { Conclusions }}$}

The results of the research methodology led to the following conclusions:

- Collaboration is required by legislation such as Title 23 of the United States Code, but methods vary, depending upon the scenario. While federal legislation requires collaboration, it does not specify specific collaborative strategies, allowing for various transportation organizations to form their own coordination plans. The inconsistencies in the plans may result in conflicts.

- The survey responses from the transportation officials indicate that funding is important to consider during the transportation planning process. Collaborative structures should be formulated with consideration of costs such as organizational implementation and the addition of more staff to support the collaborative process.

- There is resistance to a significant change in existing conditions. Based upon the survey results, most of the various organizations are willing to make small changes to their coordination plans, but not to hamper efforts and decisionmaking processes currently taking place.

- Coordination and Collaboration can occur either through a standing committee or on an ad hoc basis. The frequency and structure of the collaborative effort is dependent on how involved the organizations are, and how frequently meetings are scheduled.

- Written agreements are necessary for collaboration. A document such as an MOU is required by the FHWA and is used in some form in state DOT or MPO fields. 
- Flexibility is essential to the planning process. All parties must be willing to negotiate if disputes or conflicts arise.

In order to create an applicable collaborative work plan, each of these issues must be addressed while developing the solutions. In the next chapter, collaborative structures and management techniques will be discussed using the theory and concepts introduced in Chapters Two and Three. 


\section{CHAPTER 4. COLLABORATIVE STRUCTURES AND MANAGEMENT TYPES}

\subsection{Introduction}

The next step in the study is to define the various organizational structures and management methods that can be used for collaboration and coordination in the transportation field. The collaborative structures and management methods will then be used to provide alternative methods for collaboration, so that transportation planners have alternate options for collaborating with other agencies on transportation projects. Transportation examples will be explained in a general fashion for extended periods of use in the planning process.

As stated in Chapter Three, collaborative efforts can be created formally or when there is a specific need. There are four basic collaborative structures:

- Formalized, Hierarchical Structures

- Ad-Hoc, Hierarchical Structures

- Formalized, Non-Hierarchical Structures

- Ad-Hoc, Non-Hierarchical Structures

There are also three different management types that can be used during the collaborative process:

- Traditional, Top-Bottom Management (Forward Mapping) Approach

- Bottom-Top Management (Backward Mapping) Approach

- Horizontal Management Approach

Each of the collaborative structures and management types will be described in the subsequent sections. 


\section{2. $\underline{\text { Collaborative Structures - Hierarchical Based }}$}

\subsubsection{Formalized, Hierarchical Based Structures}

The hierarchical based collaborative structure consists of two main personnel categories: administrative people, who are responsible for supervising and approving projects and plans, and planners and engineers, who are responsible for creating and organizing project components. For example, the Metropolitan Human Services Commission (MHSC) of Columbus-Franklin County, Ohio created a structure that has been effective in policy management. The MHSC was founded in 1977 and is comprised of local government officials, human service providers, and other members representing health and education. The organization was formed as an effort to coordinate all of the human services within the Columbus Metropolitan area. The MHSC consists of an eighteen-member board of trustees and a twelve-member cabinet of executive directors, in addition to the MHSC staff. An appointed president was assigned the power of signing contracts and other important documents. All projects must be approved by a majority vote of the board of trustees. A diagram of the MHSC is provided in Figure 4.1.

This hierarchical structure can be used as an example of an intergovernmental management team because it defines stakeholder roles and it uses a voting procedure to make important decisions in large groups, or a consensus driven process in other cases. While the MHSC solves problems from the local perspective, it has been effective in supervising and managing projects such as tax levy review, addressing federal funding reductions, and developing financial allocation processes (Agranoff, 1986). 


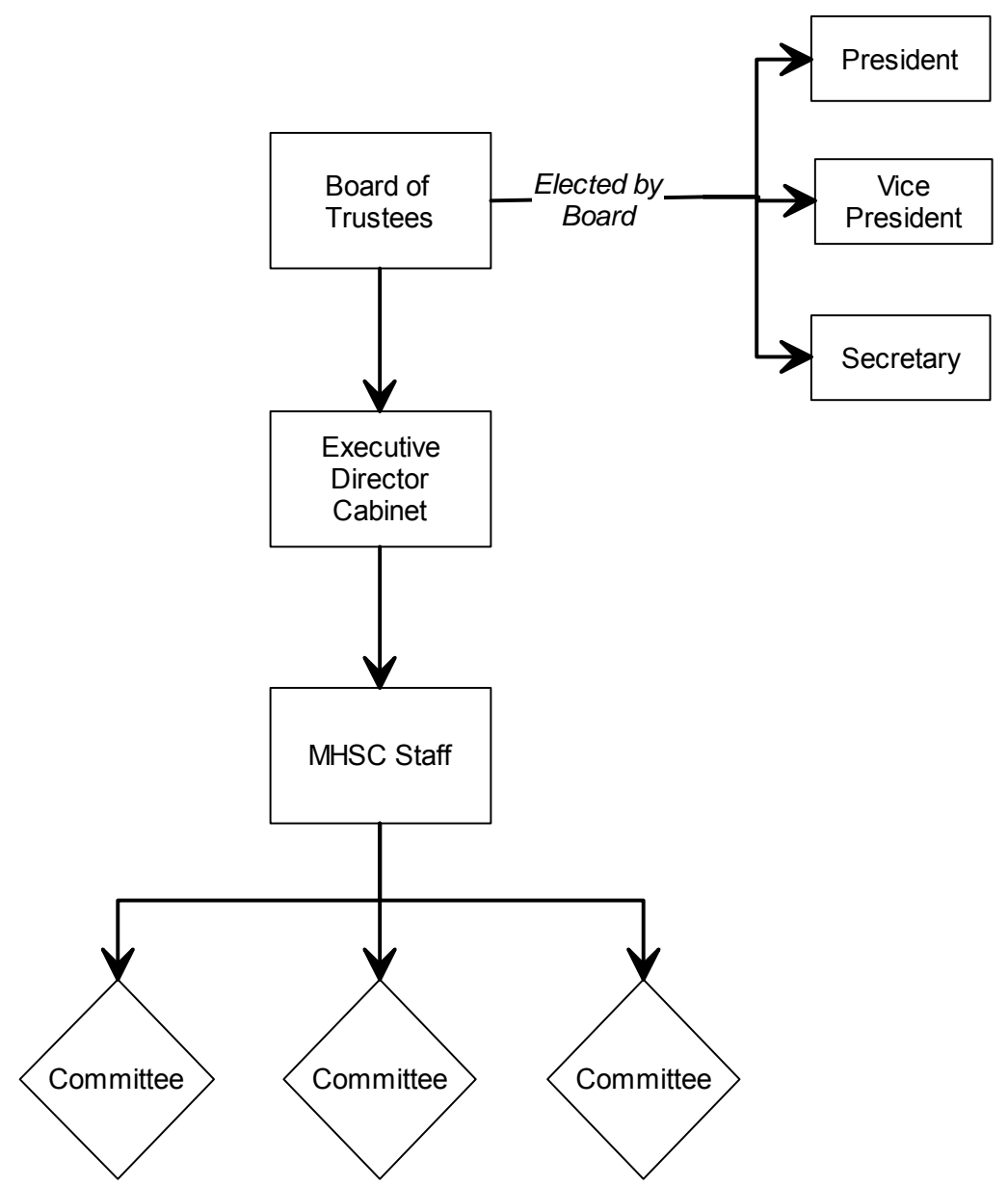

Figure 4.1 MHSC Structure (Based on Concepts in Agranoff, 1986)

A format similar to that used by the MHSC could be applied to a collaborative effort between a state DOT and MPOs. The structure would consist of a coalition of administrators from each organization. The administrators would elect a president responsible for overseeing the collaborative effort. A committee of planners, engineers, and other stakeholders whose purpose would be to address specific issues and interests, would be directly under the administrator coalition. Standing committees that are responsible for specific aspects of a project would operate under the planner, engineer, and stakeholder committee. A layout of the MHSC structure applied to transportation is provided in Figure 4.2. 


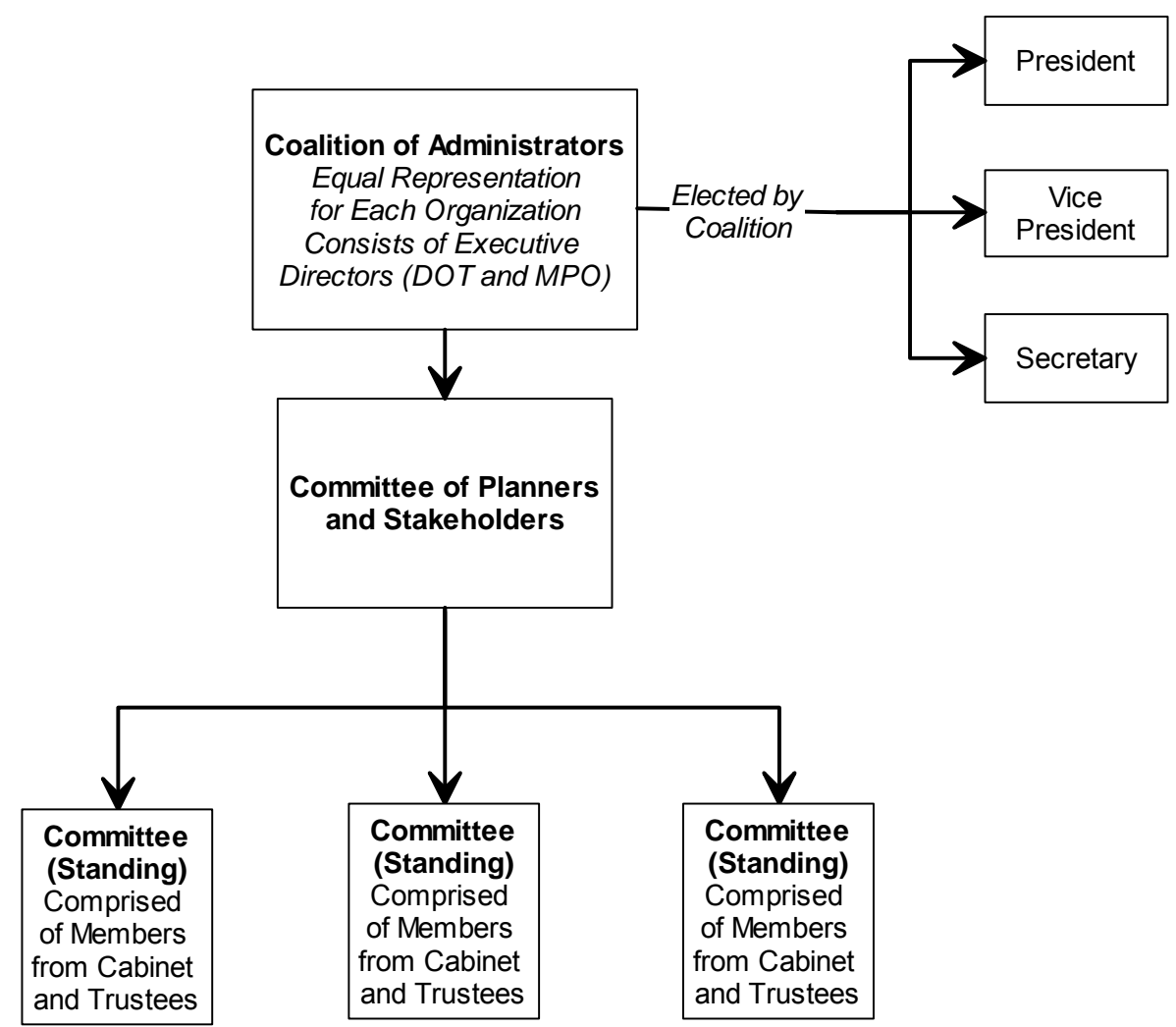

Figure 4.2 MHSC Structure, Transportation (Based on Concepts in Agranoff, 1986)

Another example of an effective collaborative structure is used by DaytonMontgomery Partnership. This organization involves the city of Dayton Ohio, Montgomery County Ohio, the United Way, Montgomery County Board of Mental Health, and the Miami Valley Regional Planning Commission (MVRPC). It is described as having a "three-level structure," with a policy group, an administrators' subgroup, and a planning group. Each of the levels is described below.

- The policy group has two representatives from each partnering organization. One of the organization's representatives is a decision maker in the agency, and the other organizational representative is an administrator or director, and serves as a supervisor and consultant to the planning group and the additional partnership staff. The director's group was created by the directors and administrators from the policy group, whose schedules were easy to coordinate (Agranoff, 1986).

- The core planning group is formed from individuals working directly in human service planning and delivery. The individuals in this group are responsible for updating their respective parent companies on the organization's progress. This 
group is led by a partnership coordinator responsible for implementing the joint venture projects (Agranoff, 1986).

- The partnership staff is responsible for assisting the core group in research and other activities. The staff could consist of members of each partnering organization, and can serve as an activity coordinator for large projects (Agranoff, 1986).

- Project ideas are brought to the attention of the policy group, which evaluates the issues and decides whether or not to proceed with further activities. Research and problem solving is conducted by on to the core planning group with the assistance of the partnership staff (Agranoff, 1986). The partnership staff and the core planning group work under the supervision of the policy group.

The Dayton-Montgomery partnership was as an example of combining the efforts of public and private organizations. Each group uses members from each of the organizations, and ensures that each party has an equal share in a project.

Applying this collaborative structure to transportation allows for a staff of coordinators devoted to the collaborative process to handle primary communication between the two managerial levels. A diagram of the Dayton-Montgomery Partnership as applied to transportation is provided in Figure 4.3.

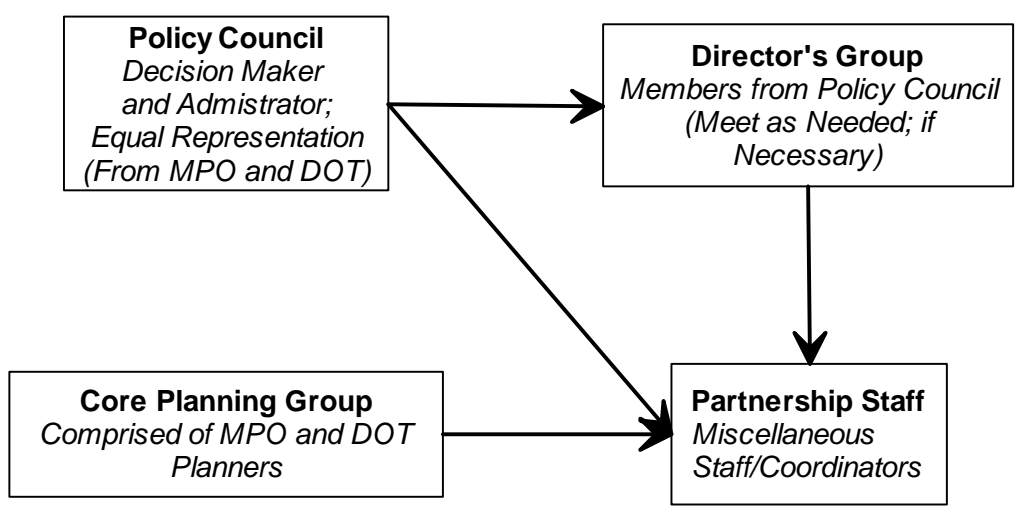

Figure 4.3 Dayton-Montgomery Partnership Layout, Transportation (Based on Concepts in Agranoff, 1986)

A notable feature of this collaborative structure is the equal representation of both organizations in the planning group and the policy council, ensuring that all 
parties have shared power in discussions. However, the planning group must seek approval from the policy council and can use the partnership staff as a medium for communication. The planning group would consist of planners and engineers from each organization, and the policy council would include decision-makers and executives from each organization.

\subsubsection{Ad-Hoc, Hierarchical Based Structures}

A hierarchical collaborative structure can also be created on an ad hoc basis. In this scenario, transportation organizations would only decide to collaborate when there was an immediate need. The organization that would be formed would also be hierarchical in nature, with administrators supervising the collaborative process. A practical ad hoc structure is provided below.

The Human Resources Commission (HRC) of Seattle-King County is comprised primarily of coalition members and task forces. The coalition also has representatives from seven organizations such as the Community Services Administration, the United Way, and Human Health Service Departments. A rotating position, called a "convenor" serves as the chairperson and schedules meetings and records meeting minutes as necessary. Task forces are organized by the policy body as necessary to address specific problems. Issues are addressed on an ad hoc basis, where committee members lead the group as necessary.

In the transportation field, the policy body would consist of administrators from each organization with equal representation for high level planners and engineers. These administrators would decide when specific task groups are necessary to solve problems, determine meeting times, and who will serve on the respective task forces. A diagram of this structure is provided in Figure 4.4. 


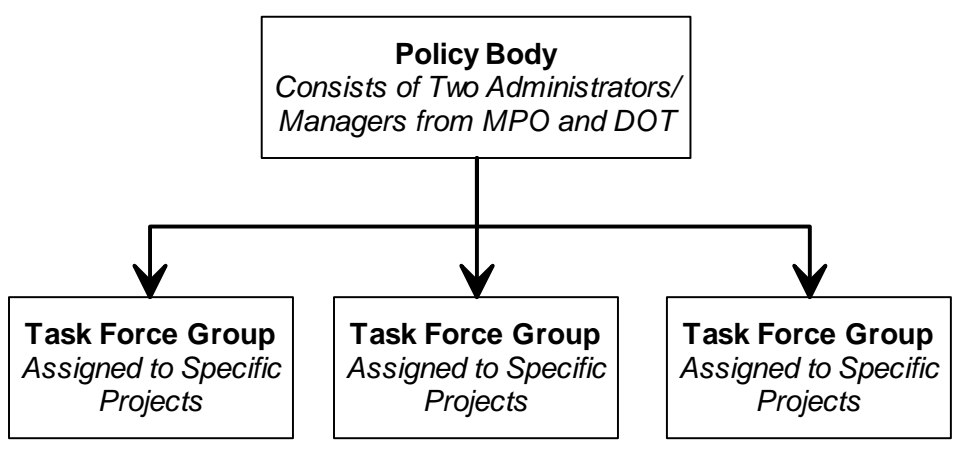

Figure 4.4 HRC Layout Applied to Transportation (Based on Concepts in Agranoff, 1986)

\subsection{Collaborative Structures - Non-Hierarchical Based}

In non-hierarchical collaborative structures, the involved individuals from each organization would share power and use a consensus driven decision-making process. An example of a committee that uses a consensus driven process is the North Carolina Interagency Leadership Team (NCILT) discussed in Chapter Three. If a decision by consensus could not be reached, dispute resolution methods such as a neutral moderator could be used to guide the process. Dispute resolution methods are discussed later in this chapter.

Collaborative structures that are not hierarchical based are also important to the transportation planning process. Planning projects such as multi-jurisdictional corridor studies, access management studies, and traffic signal coordination require various jurisdictions on the same level to work cooperatively towards a common goal. However, the collaborating agencies should agree on sharing the decision-making power and use a consensus driven strategy to reduce the chances of disputes and delays.

Similar to the hierarchical based format, a non-hierarchical based collaborative structure can be formed through a formal and informal process. Examples of each structure in its original format and in the transportation format will be described in the subsequent sections. 


\subsubsection{Formalized, Non-Hierarchical Based Structures}

An example of a non-hierarchical based structure is the helix model, where positions within a collaborative organization are plotted along a helix, as shown in Figure 4.5.

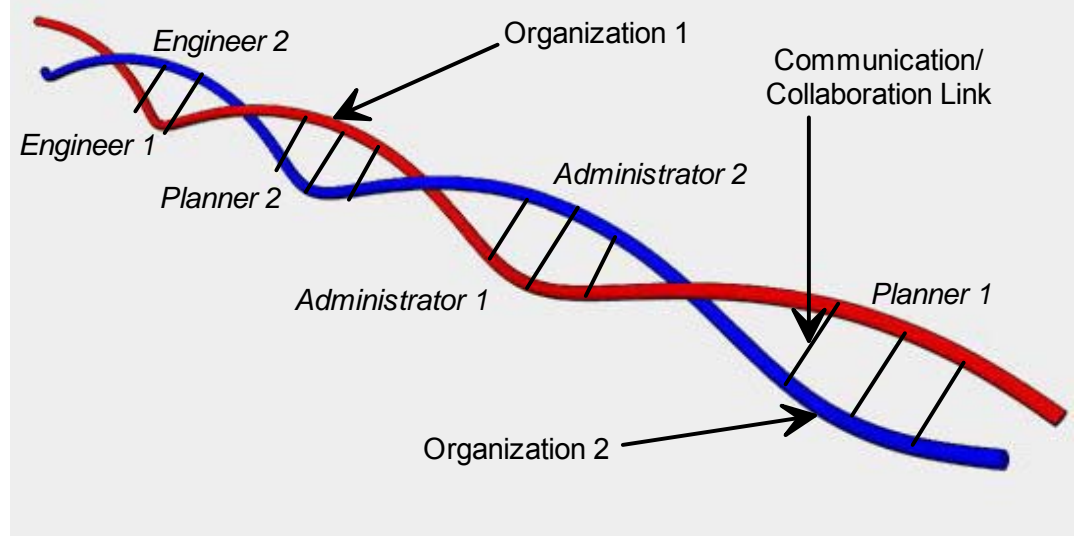

Figure 4.5 Helix Model, Double Helix Form (Based on Concepts in Kraus, 1980,

Brännback et al., 2007, and Wikipedia: The Free Encyclopedia, 2007)

In this model, no position is higher than the other, and all of the organizational positions are related and dependent on each other. This model is represented as a spiral by Kraus (1980). The following parties are indicated on the helix model:

- Task Linkers

- Process Linkers

- Structural Linkers

- Technology Linkers

- Planning Linkers

- Environmental/Culture Linkers

- Subsystem Linkers

- Coordinating Linkers

- Objective Linkers 
Kraus does not specify if each of these parties should be involved in the organization or whether some tasks could be combined. Alternatively, other reports have illustrated the helix model in the double helix form.

This model provides a visual example of how parties from various organizations could be connected, and provides communication contacts during the collaborative process. However, Kraus did not specify a management strategy, allowing for a variety of strategies to be used. However, a consensus based decision process would be used for this model since all of the involved parties would share the decision-making power.

The transportation helix model uses concepts from both of the original forms. As already stated, this model is best used for collaborating organizations that are on the same hierarchical level. The helix model has the ability to be used in multiple projects because it does not specify specific people or parties. For example, the helix model could be comprised of planners and engineers, or administrators from each collaborating organization. A moderator or coordinator could serve as the link between the two organizations.

Another non-hierarchical based collaborative structure was created by WILMAPCO, the MPO in the Wilmington, Delaware metropolitan area. This MPO has created various subcommittees dedicated to solving specific transportation issues. For example, the congestion management system (CMS) subcommittee is responsible for congestion issues in the metropolitan network, and produces annual reports, which designate problematic areas that require action. The main organizations that are involved with the MPO, and could be involved with the CMS subcommittee include:

- Principal city planners

- Transportation planners

- Maryland Department of Transportation (MDOT) representatives

- Delaware Department of Transportation (DDOT) representatives

- City of Wilmington, Delaware members

- States of Delaware and Maryland Governor Office representatives 
- Cecil and New Castle County Representatives

WILMAPCO is an example of an MPO that has made a formal effort towards solving congestion management issues. It is also unusual in that it crosses a state border and involves coordination and collaboration through various transportation organizations. Its annual report, which indicates its problem solving process, and the organizations represented in the MPO, can help to determine which organizations could be represented in a multi-jurisdictional effort. A layout of the WILMAPCO CMS subcommittee applied to transportation issues is shown in Figure 4.6.

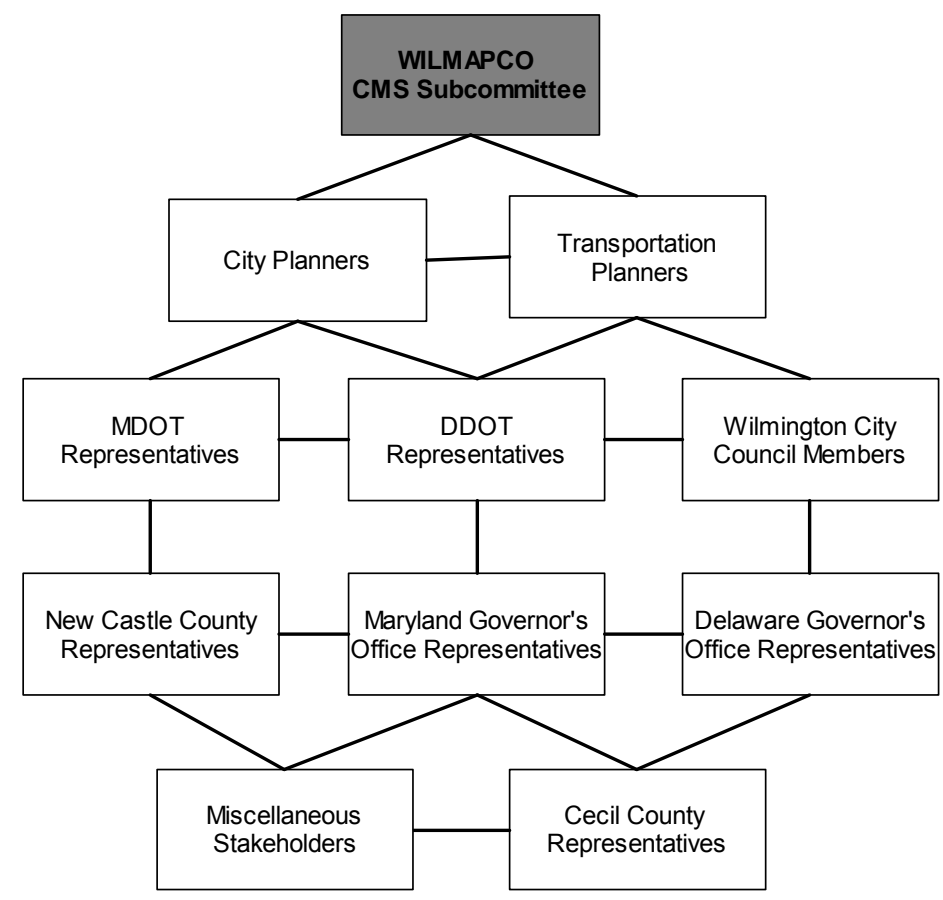

Figure 4.6 Potential WILMAPCO Subcommittee Layout (Based on Concepts in WILMAPCO, 2006)

\subsubsection{Ad-Hoc, Non Hierarchical Based Structures}

A non-hierarchical based collaborative structure can be created on an as needed basis to address specific issues or continue communication between collaborating organizations. Two examples of ad hoc structures are described below.

The Regional Transit Association (RTA) in San Francisco, California has communicated on a regular basis with other agencies in the metropolitan area such as 
the Metropolitan Transportation Commission and the San Francisco Bay Area Rapid Transit (BART) system. To coordinate and communicate with other agencies, the RTA established an opportunity for communication to occur between the various local transit agencies. The Board of Control forum is shown in Figure 4.7.

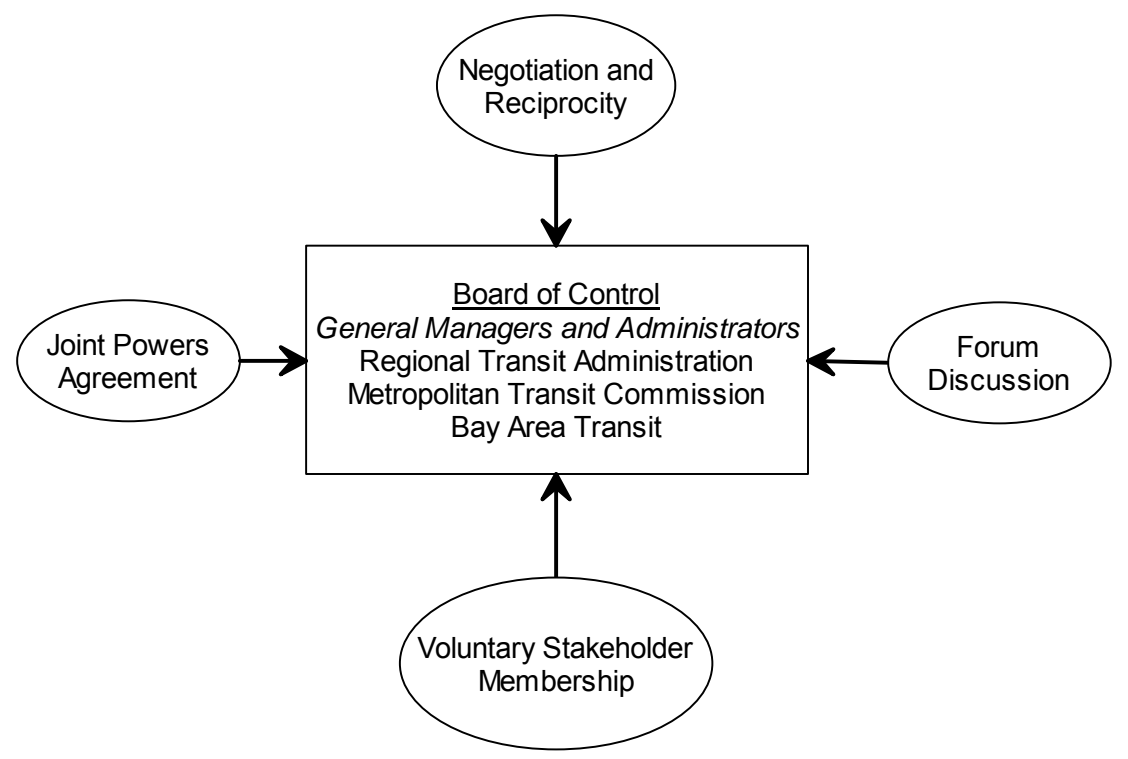

Figure 4.7 RTA Board of Control Forum Layout

(Based on Concepts in Chisholm, 1989)

The Board of Control forum consists of the general managers of each of the involved organizations (RTA, Metropolitan Transportation Commission, and BART). The administrators stress negotiation, which involves the stakeholders compromising on their personal goals to reach an agreement. Another component of the Board of Control forum is reciprocity, where the stakeholders will treat the other forum participants as they wish to be treated (Bendoly and Swink, 2007). However, the Board of Control forum was ineffective at first due to power struggles between the stakeholders. A joint-powers agreement was established to address this issue (Chisholm, 1989).

This collaborative method is flexible because attendance and membership at meetings is voluntary. Meeting discussions can go in any direction, and do not necessarily have to meet specific goals. However, a minimum set of standards must be met for each meeting, ensuring that the basic goals are addressed. This method is 
based upon a joint-powers agreement, which ensures that all involved parties have shared power during meetings (Chisholm, 1989). The attendees could use a consensus driven decision-making process to address issues.

An alternative method of collaborating with other organizations on a similar hierarchical level is by designating a representative to attend the other party's meetings. This option would make the visiting party aware of the partner's operations and allow for open discussion opportunities. This communication option was indicated as a coordination and communication method by a response from one of the surveyed states. This method is also flexible; any representative from one organization could attend the other's meeting.

\subsection{Management Strategies}

In addition to determining the best collaborative structure for collaborating transportation organizations, a method of managing the organization should also be determined. As stated previously, there are three methods of managing a collaborative organization: forward mapping, backward mapping, and horizontal management. Each management type will be described in this section.

\subsubsection{Traditional, Top Bottom Management (Forward Mapping) Approach}

The forward mapping management approach is the most common approach used in a hierarchical based collaborative structure. It involves the administrators creating a specific mission statement. Specific tasks are assigned to parties in the lower hierarchical levels, with a description of a favorable product dependent on the

original mission statement at the bottom level (Williams et al., 1982). A diagram of the decision-making process is provided in Figure 4.8. 


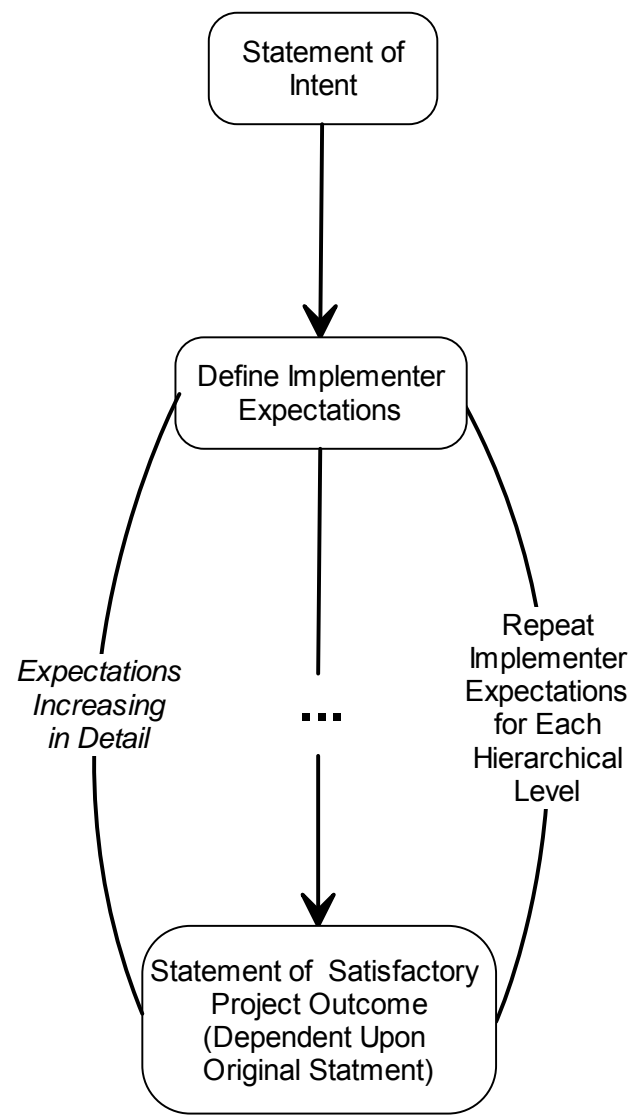

Figure 4.8 Forward Mapping Decision Process

(Based on Concepts in Williams et al., 1982)

This organizational method has been used by various organizations to address issues and manage projects. However, this method is somewhat restrictive, because it assumes that the policymakers are solely responsible for the factors that affect policy implementation (Williams, et al., 1982). In order to provide policymakers with flexibility during the planning process, alternative organizational management methods will be further analyzed in this chapter.

\subsubsection{Bottom-Top Management (Backward Mapping) Approach}

As stated in Chapter Three, the backward mapping approach uses the "bottom-to-top" problem solving method, where the problem is formulated by the parties who are closest to the problem or could be directly affected by its outcome. A diagram of the backward mapping management process is provided in Figure 4.9. 


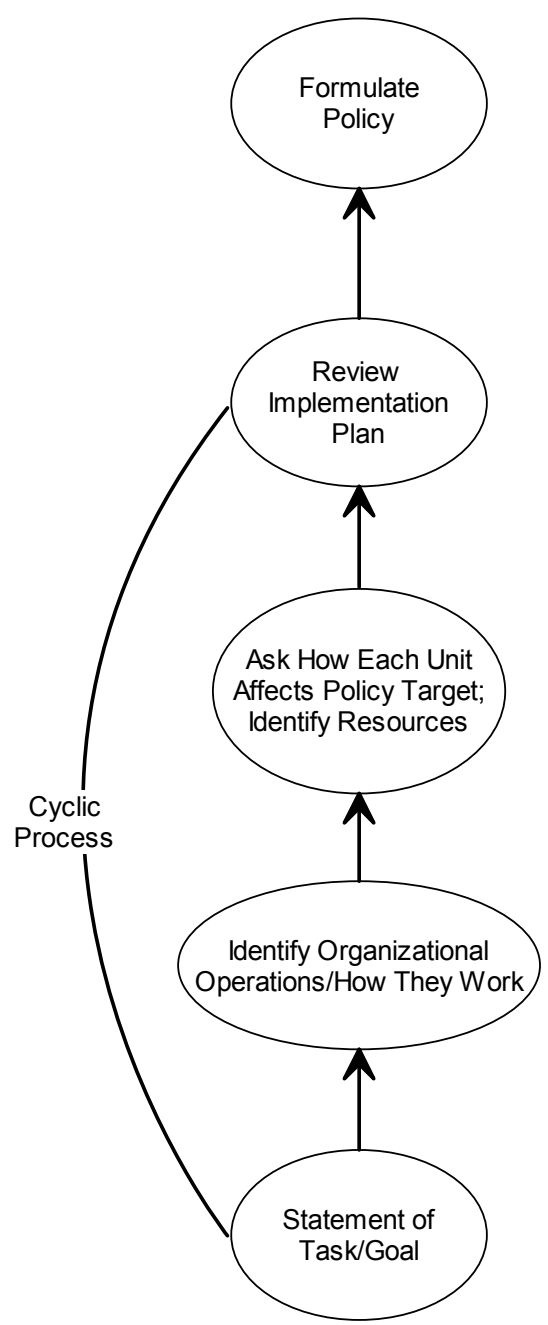

Figure 4.9 Backward Mapping Decision Process

(Based on Concepts in Williams et al., 1982 and Dyer, 1999)

According to the figure, the process begins at the bottom of the hierarchical level, with the parties who are most affected by the plan defining a statement of their task or goal. At each hierarchical level, the group should identify its organizational operations, how they work, how the group will affect the project, and identify resources necessary to complete the project. This process is used at each hierarchical level. When the policy components reach the top hierarchical level, they review the components and formulate the plan after a thorough review of the implementation path. The process could be repeated as necessary in order to address and modify specific issues. 
Many authors or organizations that have used this management structure in their organizations have used Richard Elmore's definition of Backward Mapping to create their decision-making process. An example of an organization that has used the backward mapping process is the Environmental Protection Agency (EPA) and their Sustainable Industry Project (SIP). The SIP was developed to implement new policy recommendations that would eliminate progress barriers and promote strategic protection in the environmental industry (U.S. EPA, 1994). Through the use of expert panel meetings, "drivers" and "barriers" to innovation were identified by the parties that are most affected by the regulations. The panel meetings addressed the following issues:

- Promote cleaner environmental performance.

- Promote cost effectiveness.

- Encourage cooperative involvement among stakeholders.

- Promote innovative and effective actions by EPA, states, sustainability.

- Have capacity to affect long term thinking and action toward sustainability.

- Feasibility

Once the EPA is aware of the opinions of the industries that adhere to their policies, they can design future plans and policies that allow for flexibility and take the stakeholders' opinions into account. A diagram of the SIP is provided in Figure 4.10. 


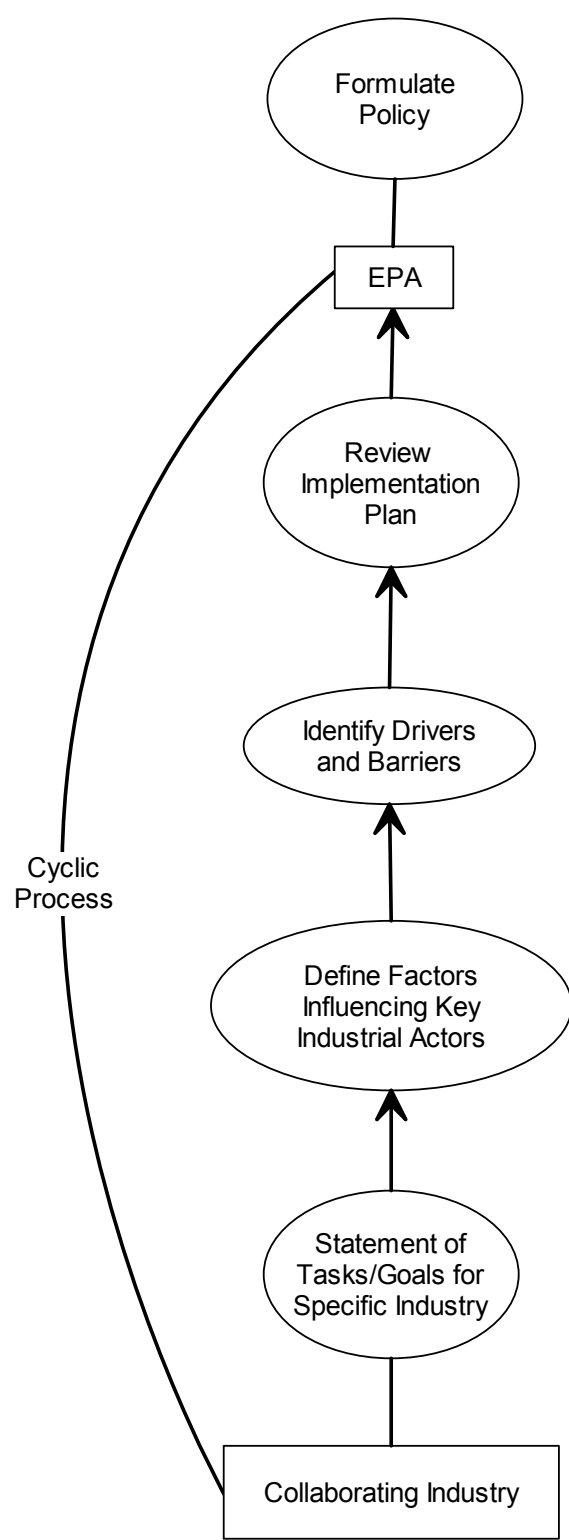

Figure 4.10 SIP Decision-making Process

(Based on Concepts in U.S. EPA, 1994, and Williams et al., 1982)

The backward mapping approach would be beneficial for collaborative efforts in the transportation field because common issues could be identified and addressed by the parties that are closest to the problem, such as the public or planners and engineers responsible for designing specific components of the solution. In addition, the solutions created by the parties at the lower hierarchical levels can be reviewed by administrators to determine how practical they are to the organization's planning 
goals. A diagram of the backward mapping process in the transportation field is provided in Figure 4.11.

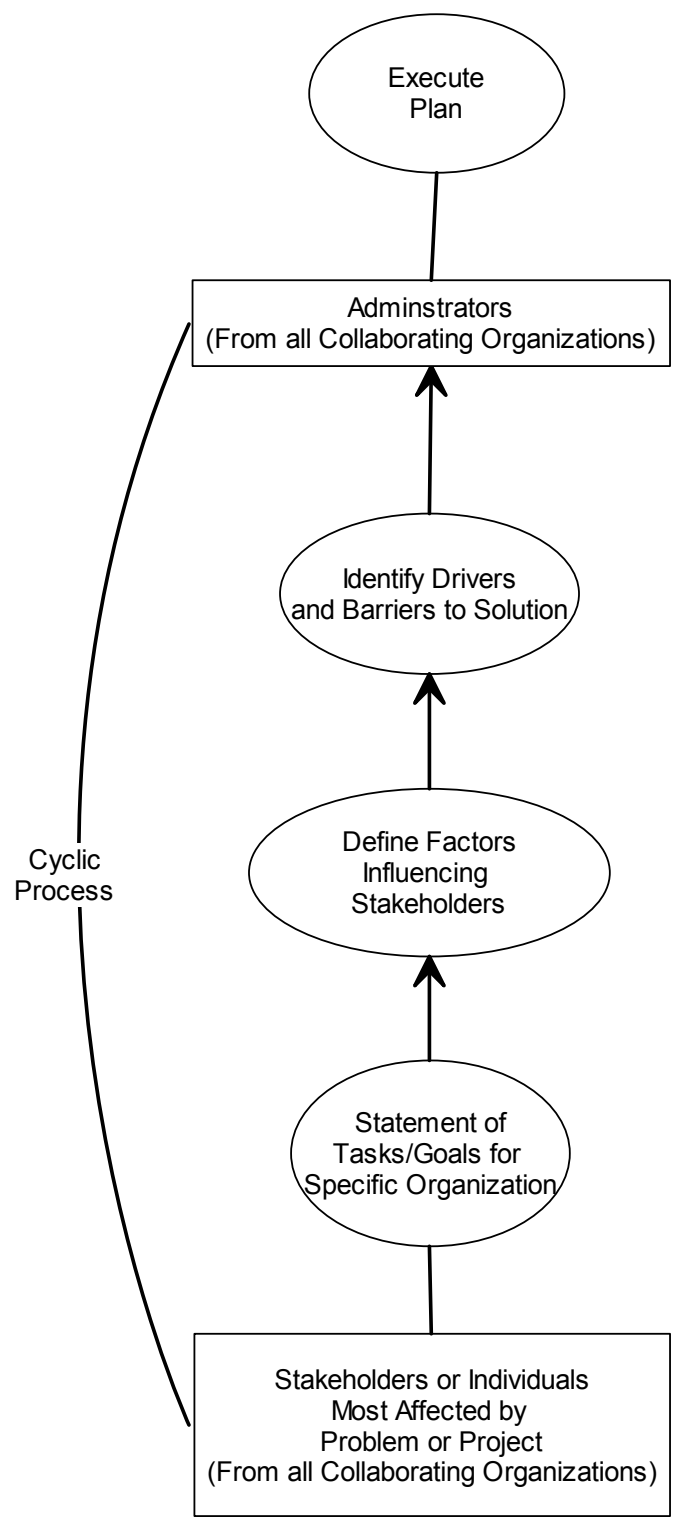

Figure 4.11 Backward Mapping Process, Transportation

(Based on Concepts in Williams et al., 1982, Dyer 1999, and U.S. EPA, 1994) 


\subsubsection{Horizontal Management Approach}

The horizontal management approach involves all of the stakeholders having equal power in the decision-making process. An example of horizontal management is the jurisdiction based model, which was developed by researchers to define collaboration and coordination in a horizontal fashion. This differs from top-to-bottom descriptions and bottom-to-top descriptions. A model was developed after surveying 237 cities about how they collaborate with other organizations and to the extent of which they collaborate with each other. As a result, a model was developed to measure the extent to which a city practices intergovernmental management, and is identified as the base characteristics of the jurisdictional-based model for intergovernmental management. The variables are (Agranoff and McGuire, 1998):

- Total Intergovernmental Activity (dependent variable)

- Bargaining Behavior (explanatory variable)

- Formal Adjustment Behavior (explanatory variable)

- Strategic Activity (explanatory variable)

- Internal Barriers (explanatory variable)

- "Intersectoral" Policy Leadership (explanatory variable)

- Importance of State Government (explanatory variable)

- Contact with other Cities (explanatory variable)

- Policy Activity (control variable)

The results of Agranoff and McGuire's survey indicate that the two variables that have the most important factor on the jurisdiction based model are "intersectoral" policy leadership and policy activity. In addition to a discussion of the model, examples of cities using jurisdictional-based intergovernmental management in their policy activities are discussed. An example of a city that uses jurisdictional-based intergovernmental management is Salem, Indiana. Salem coordinates efforts with other cities through an organization called ArA Associates. ArA is an organization comprised of 13 small cities (Agranoff and McGuire, 1998). A diagram of the jurisdictional intergovernmental management model is shown in Figure 4.12. 


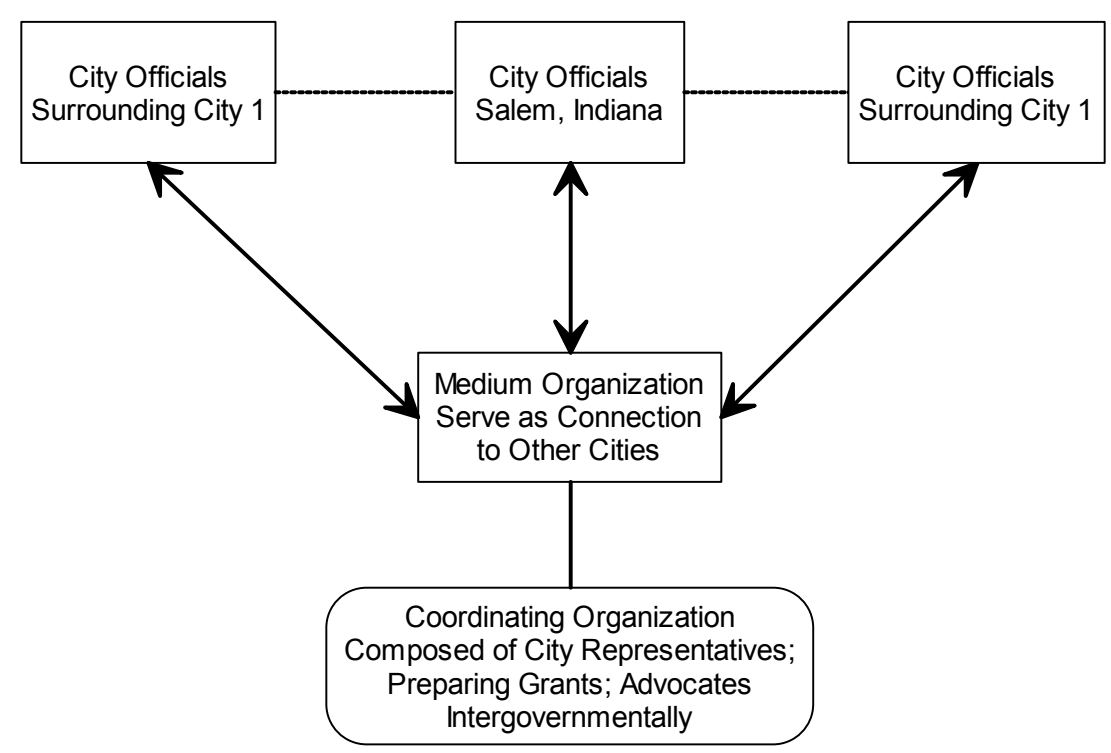

Figure 4.12 Jurisdictional-Based Model for Salem, Indiana

(Based on Concepts in Agranoff and McGuire, 1998)

While this example of the jurisdictional-based model does not describe general management features, the variables used to analyze the cities can be used as performance measures for a transportation organization to measure the extent of their current collaborative efforts, identify issues, and identify how to address them. The variables discussed in the previous section were included in the survey sent to the various cities. A rating was created for each variable. The model also allows for flexibility between collaborative efforts as multiple examples of practices for each of the variables could be defined. An example of the jurisdiction based model as it applies to transportation is provided in Figure 4.13. In this case, the two collaborating organizations are cities, with the MPO overseeing the communication process. 


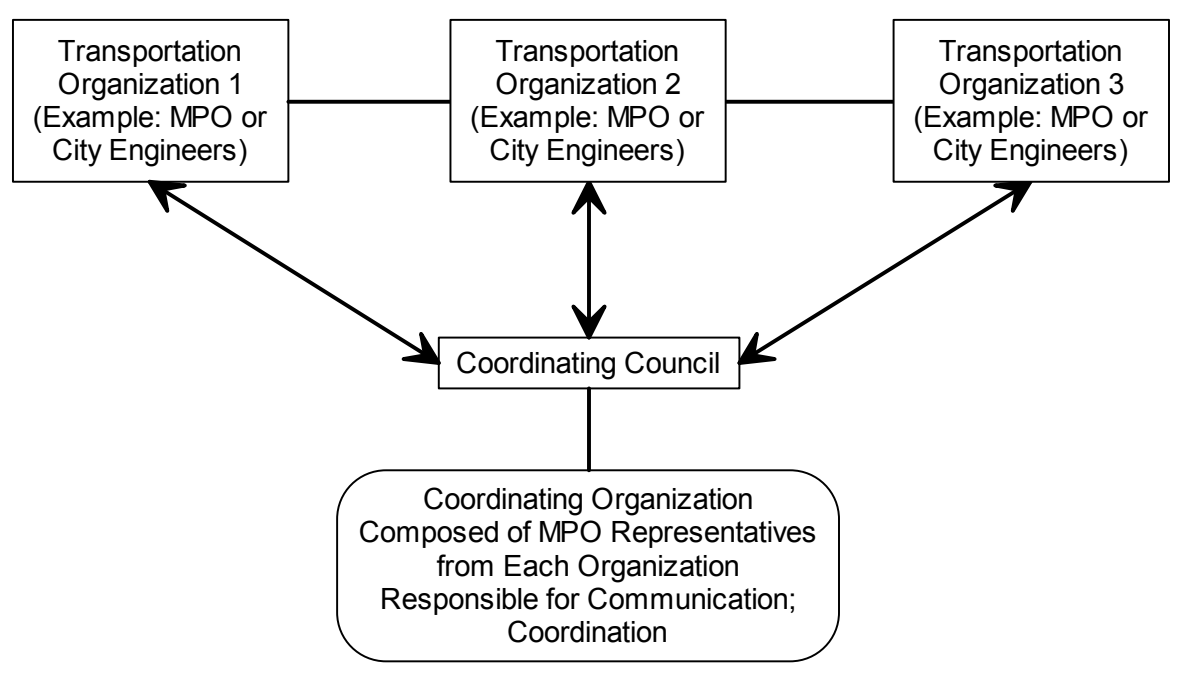

Figure 4.13 Jurisdiction Based Model, Transportation (Based on Concepts in Agranoff and McGuire, 1998)

\subsection{Organizational Structures and Management Applied to Transportation}

As stated in Chapter Three, the Ronald Reagan Corridor Master Plan was developed through a collaborative effort between four adjacent towns within Hendricks County. During the planning process, there were discrepancies between the various jurisdictions' land use plans. In order to prevent the discrepancies from delaying the overall planning process, the management methods and organizational structures described in this chapter can be used.

Throughout the planning process, a steering committee composed of representatives from each jurisdiction was assigned to act as a "sounding board" for planners and decision-makers (HNTB and Hendricks County, 2005). The steering committee can also be used in the Salem, Indiana jurisdictional management model as the neutral party that is responsible for communication between the various cities. The steering committee could oversee the project's process, establish communication between the various agencies, and serve as a moderator for land use planning and dispute resolution meetings. The steering committee can alert the various jurisdictions about land use discrepancies that could lead to disputes and project delays. A diagram of the jurisdictional-based management using the helix model is provided in Figure 4.14. 


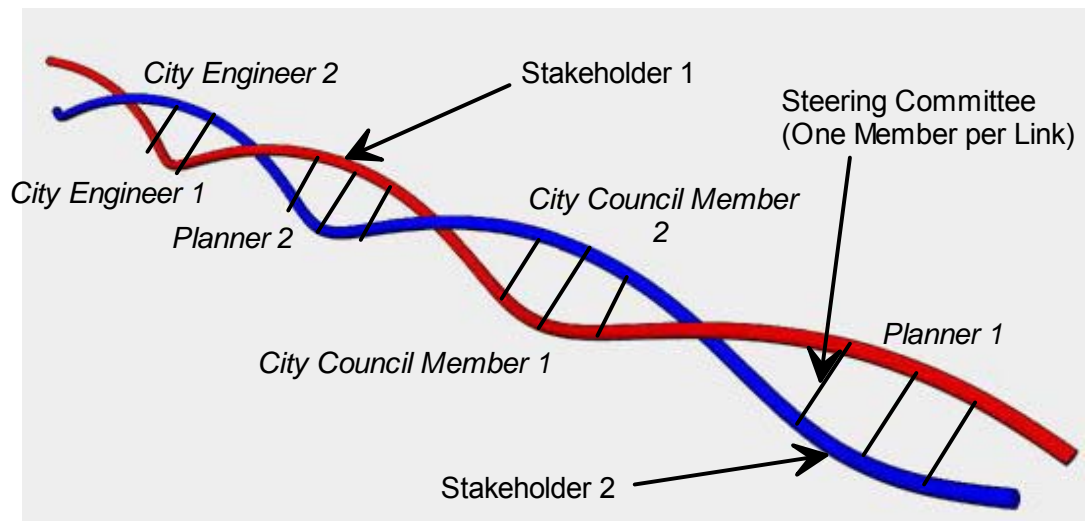

Figure 4.14 Jurisdiction Communication Using the Helix Model (Based on Concepts in HNTB and Hendricks County, 2005, Kraus, 1980, Brännback et al., 2007, and Wikipedia: The Free Encyclopedia, 2007)

Alternatively, the backward mapping management model could be used in cases with organizations on different hierarchical levels such as a city collaborating with the county. The same characteristics of the framework outlined in Error! Reference source not found. can be used for this scenario as well. The steering committee used in the Ronald Reagan Corridor can be used as the moderator or coordinator. Figure 4.19 illustrates this process using the Dayton-Montgomery County organizational structure. 


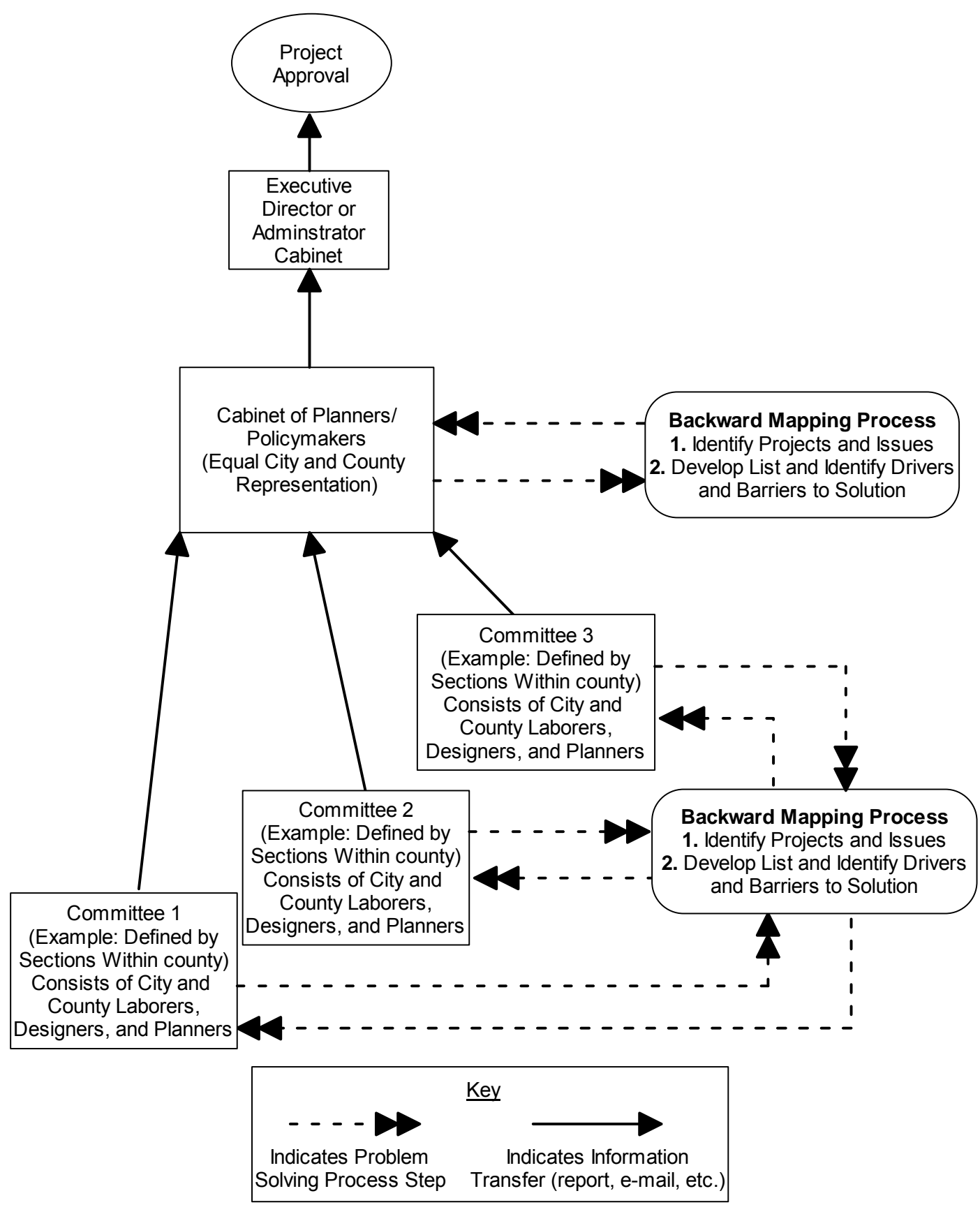

Figure 4.15 Backward Mapping Model, City-County Relationship (Based on Concepts in Williams et al., 1982, Dyer, 1999, U.S. EPA, 1994, and HNTB and Hendricks County, 2005) 


\subsection{Dispute Resolution Methods}

The dispute resolution methods discussed in Chapter Three can serve as effective methods of addressing issues, because most of the methods have been developed and modified by the construction management industry, where disputes are commonplace. A diagram showing the dispute resolution methods is provided in Figure 4.16.

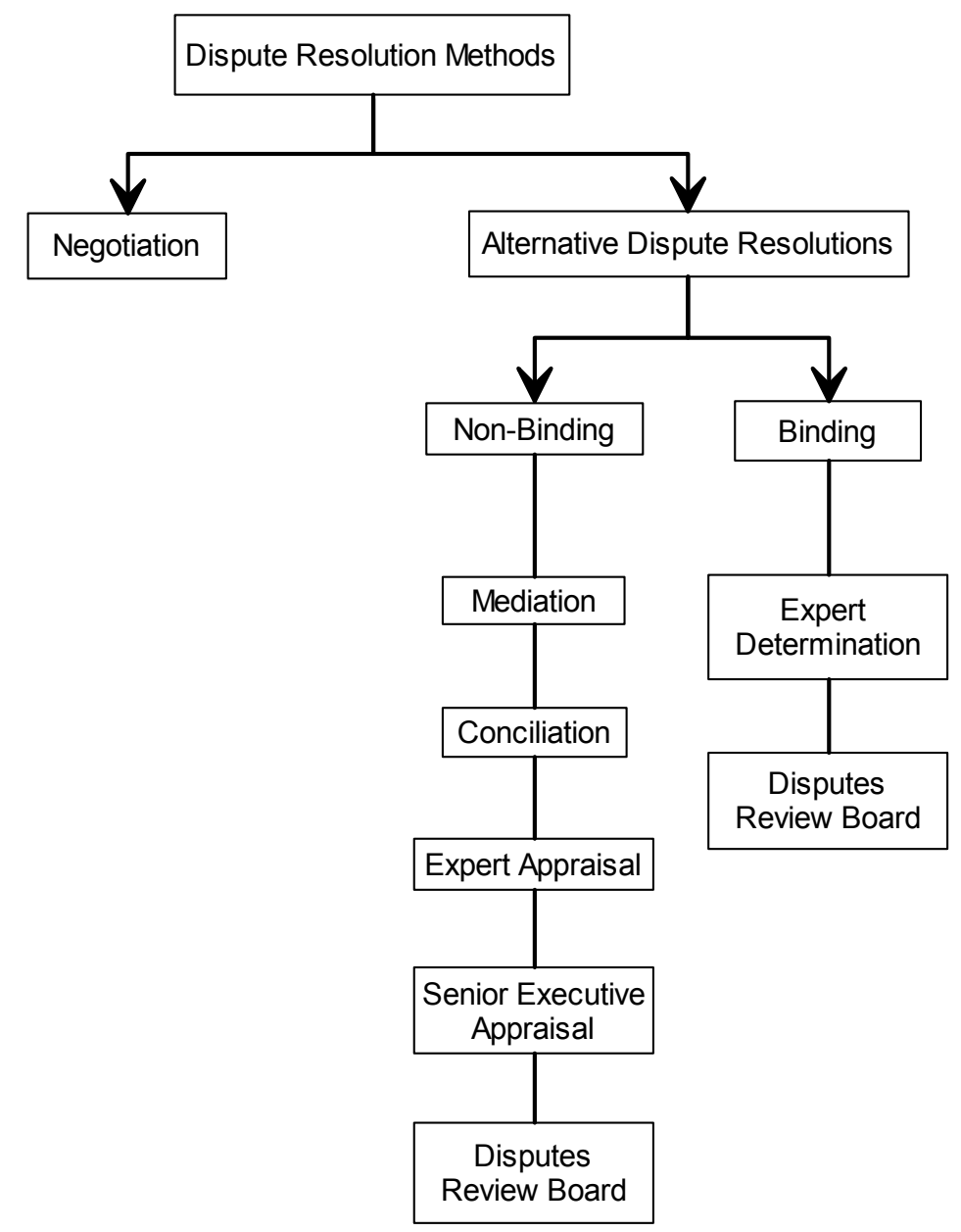

Figure 4.16 Dispute Resolution Method Diagram

(Based on Concepts in Carmichael, 2002)

\subsection{Memoranda of Understanding in the Collaborative Process}

The existing guidelines of the MOU should be used for future planning projects. However, the organizational structures and the management types can serve to make 
the document more specific. For example, the organizational structure and the decisionmaking process can be described while introducing the organizations that will be involved in the project. Using collaborative structures provides specific roles within each involved organization and identifies the administrators.

\subsection{Conclusions}

The models described above should provide definitive coordination structures that will open more doors to communication and manage the collaborative efforts after implementation. These structures and management types were formulated for flexibility between collaborating organizations in choosing structures and management types. While there may be variations to collaborative structures discussed in this chapter, the four basic collaborative structures and the three management types are guidelines for a collaborative organization. In general, the collaborative process is iterative in nature, but over time the structures and management types will benefit the parties and organizations involved. 


\section{CHAPTER 5. STUDY CONCLUSIONS}

The purpose of this study was to identify the best methods to facilitate collaboration in transportation planning. Specifically, the study covers the coordination that is needed when transportation projects involve multiple jurisdictions. For example, a corridor project may pass through at least one city, at least one county, and involve a highway on the state network. Concepts and practices regarding collaborative structures and management types in other disciplines, such as management and economics, were identified and adapted for possible use in transportation planning. Based on these findings, a collaborative structure and management technique is recommended for each study. The structures are presented in this chapter in a way that allows their integration into current planning and collaboration strategies.

When developing collaborative structures, it is important to consider factors that might affect the problem solving process. Common factors are costs, determining the stakeholders that will have the decision-making power in the collaborative process, and the integration of proposed collaborative structures into existing planning processes. These factors, as described in Section 3.8, were identified by transportation officials as important features to the collaborative process in transportation planning.

\subsection{Suggested Collaborative Structure and Management Technique - Multi-} Jurisdictional Issues Related to Congestion Management

\subsubsection{Collaborative Structure}

When organizations such as cities, counties, INDOT and MPOs work together on multi-jurisdictional projects, they could use the Board of Control Forum discussed in Section 4.3.2 of this report and coordinate their activities using the jurisdictionalbased model of intergovernmental management as discussed in Section 4.4.3. The 
Board of Control Forum is an ad hoc collaborative structure. It allows for collaborating organizations to work together on specific planning or development issues where planning components overlap, such as a corridor study, traffic signal coordination, and corridor access management. Because this study involves different organizations conducting various transportation planning activities, it may be better to create an organization when the problem arises rather than use a hierarchical structure that may not be adaptable to all transportation planning issues. This organizational structure and problem solving process would have lower costs to the stakeholders, because they would not have to commit current individuals or hire new people to maintain a formalized structure. The jurisdictional-based model for intergovernmental management is useful for instances when multiple organizations have similar governmental powers (city-city, county-county, etc.). Using a hierarchical structure in this case could possibly result in disputes and delays to transportation projects. In addition, the MPO forum provides opportunities for discussion between necessary parties, where a formalized structure may include stakeholders that may not need to be involved in every dispute or discussion.

As discussed in Section 4.4.3, the Board of Control Forum is entirely voluntary, where power would be shared by the stakeholders (Chisholm, 1989). The stakeholders would use a consensus-driven process as discussed in Section 3.4.1 to determine solutions. If a consensus cannot be reached, a moderator agreed upon by the stakeholders (similar to the Massachusetts example discussed in Section 3.4.2.2) could be employed to guide the process.

The individuals who would be involved are dependent on the organizations participating in the collaborative effort. The steering committee used by the stakeholders in the Ronald Reagan Corridor Study, which was discussed in Sections 3.3 and 4.5.2, provide examples of officials involved in the process. The officials are (HNTB and Hendricks County, 2005):

- County Commissioners

- County Councilmen

- Town or City Council Representatives

- Town or City Planners 
The contacts that were provided by the Indiana MPO Council (see the previous section) could also be involved in the collaborative process.

Figure 5.1 shows the management structure for the collaborative effort and Figure 5.2 shows the MPO forum layout, which is based on the Board of Control Forum discussed in Section 4.3.2.

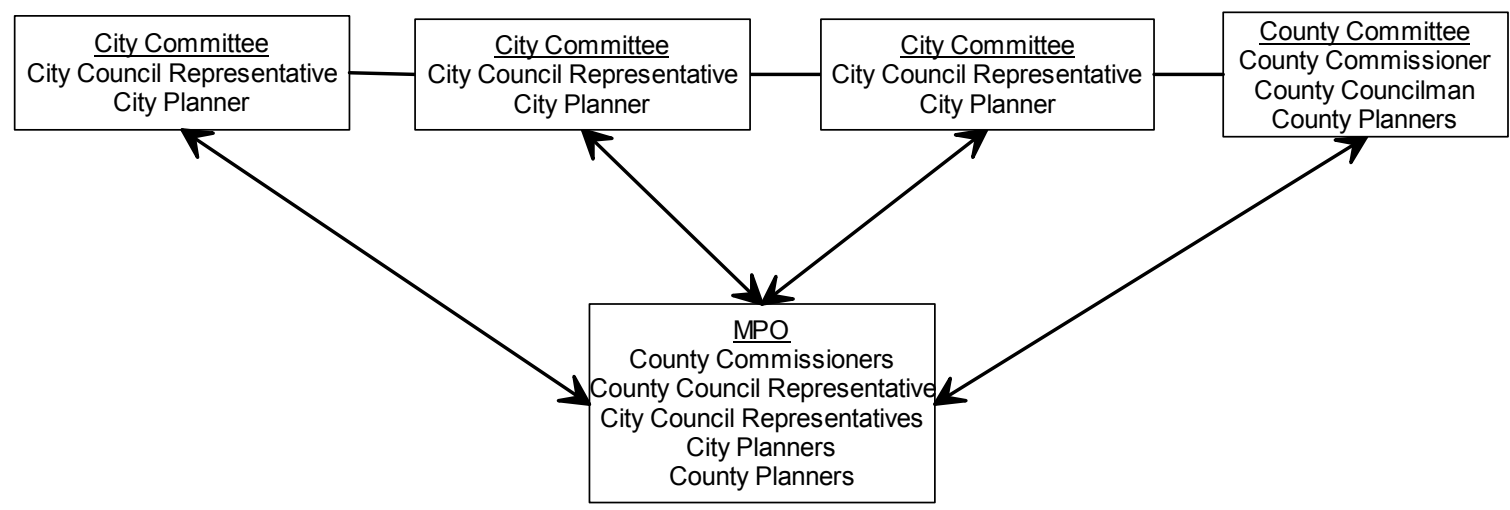

Figure 5.1 Multi-Jurisdictional Collaborative Structure (Based on Concepts in HNTB and Hendricks County, 2005 and Agranoff and McGuire, 1998)

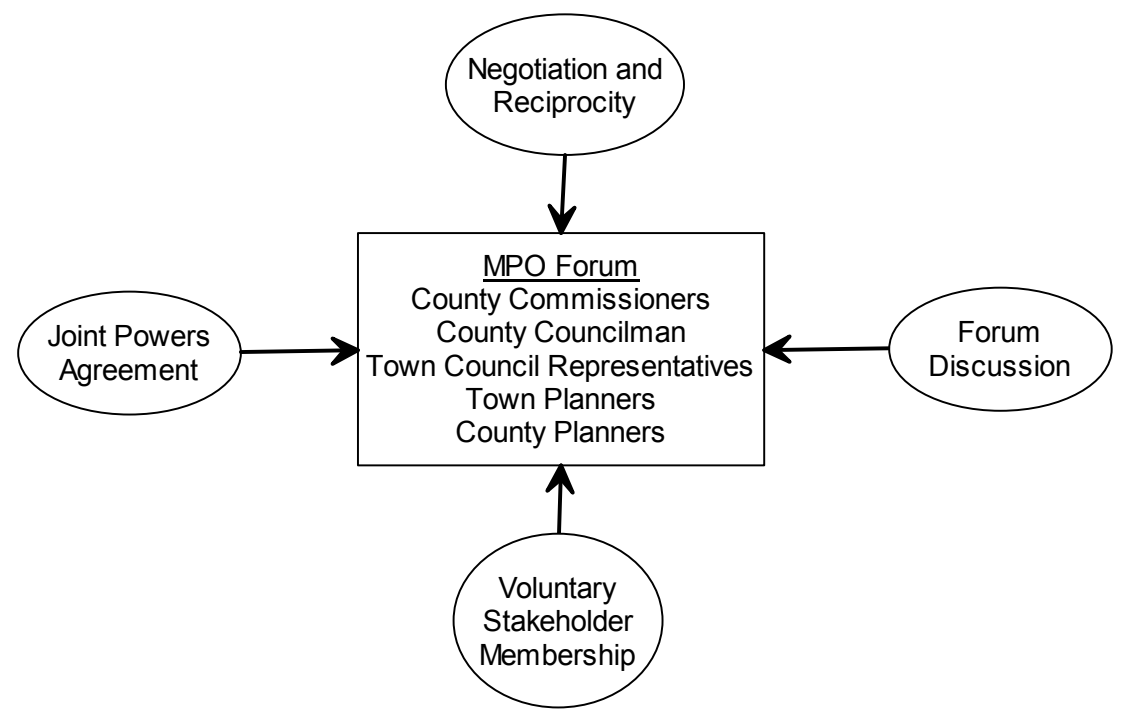

Figure 5.2 MPO Forum

(Based on Concepts in HNTB and Hendricks County, 2005 and Chisholm, 1989) 


\subsubsection{Problem Solving Process}

In order to manage the collaborative process, the collaborating organizations should use the jurisdictional-based model developed by Agranoff and McGuire (1998), which was discussed in Section 4.3.2 and is presented in Figure 5.3. Because some of the collaborating organizations may be on the same governmental level (i.e., cities and counties), using a process where the stakeholders share the power would reduce the chances of conflicts resulting from leadership power struggles. In the making of the Ronald Reagan Corridor Master Plan, the "steering committee" was used by the stakeholders as the coordinating organization during the process. By virtue of its ongoing role in transportation planning and programming matters, the MPO provides the basis for the collaboration activity in multi-jurisdictional projects. (In areas not covered by an MPO, the regional planning organization, if one exists, can assume that role.) The other elements of the suggested management process are:

- Although the "MPO Forum" in Figure 5.4 is made up of officials from (or chosen by) the MPO, it is important to have meaningful input from stakeholders. Members of the forum can serve as coordinating contacts for those stakeholders who cannot attend a meeting of the forum. The group should select an individual to convene, oversee, and document the coordination meetings.

- When there are elements of a plan or process where conflicts could arise, the coordination contact would inform the stakeholder committee, which in turn would inform the remaining stakeholders of the other organization's plan or process. This process would be repeated as conflicts arise.

- The MPO forum can be used to keep the stakeholders updated during the planning process. Disputes can be brought to the attention of the MPO by the coordination contacts.

\subsection{General Study Findings}

In general, the following can be concluded about organizing and managing collaborative organizations. 
- Constant review and evaluation of collaborative efforts are necessary in order to improve the planning process. For example, the Indiana MPO Council Handbook, which guides MPOs through the planning process, is a "living document" that is reviewed and modified if policy or organizational changes occur (Indiana MPO Council, 2007).

- Flexibility is important to maintain throughout the development and management process. Flexibility includes (a) accommodating the schedules of the participants, (b) being aware of the objectives and constraints that other participants have, and (c) being open to changes from traditional planning strategies. (Chisholm, 1989)

- The early stages of collaborative efforts can be time consuming, especially when officials and organizations have not worked together previously. However, if the stakeholders are actively involved in the collaborative effort, and desire to work towards a common goal, then all organizations will benefit (Huxham and Vangen, 2005).

- While collaborative structures and management strategies can help organizations collaborate with each other, they are only one component of a successful partnership. During the development phase of the partnership, each organization should assign "champions" to lead the collaborative effort. As stated in Chapter Two, "champions" are individuals who believe in the organization and are committed to working for the benefit of the organization or collaborative effort. Examples of individuals who could be "champions" include the INDOT Local Assistance Liaison and District Development Engineer (Indiana MPO Council, 2007), who collaborate with organizations such as the MPO.

As a project is developed, the administrators or managers can include the lessons learned during the collaborative process as a component in the activities report. An example of performance-based measurements was introduced with the jurisdictional-based model. The performance measures used by Agranoff and McGuire (1998) and discussed in Section 4.4.3 were determined to be the most significant factors that affected collaboration in intergovernmental management. The factors can be used as criteria to critique the collaborative process upon completion. However, the managers can develop their own set of performance measures, if necessary. 


\subsection{Suggestions for Future Work}

While this study provided suggestions for collaborative strategies in the transportation field, the next step in the process would be for two organizations, such as an INDOT district and an MPO to adapt these strategies to their policymaking activities and provide feedback. This will allow for the collaborative structures and management techniques to be refined exclusively for transportation. The feedback and suggestions obtained from the officials participating in the process can be used as additional performance and evaluation measurements for future collaborative efforts. Another concept for future work can focus on organizational behavior in relation to the stakeholders who are involved in the process. Nevertheless, this study provides transportation officials with a series of guidelines that can tested and compared to current collaborative strategies. As collaborating organizations refine the ways in which they work together, the results of collaboration can be achieved with greater effectiveness and efficiency; to the benefit all involved organizations. 


\section{LIST OF REFERENCES}

$102^{\text {nd }}$ Congress (1991). “Title I - Intermodal Surface Transportation Efficiency Act of 1991 (ISTEA) - PL 102-240." Bureau of Transportation Statistics. Retrieved 28 August 2006 from, <http://www.bts.gov/laws_and_regulations/docs/ istea1.htm>.

$105^{\text {th }}$ Congress (1999). "Title 23, United States Code." United States Department of Transportation/Federal Highway Administration. Retrieved 1 September 2006 from, <http://www.fhwa.dot.gov/legsregs/title23.pdf>.

$109^{\text {th }}$ Congress (2005) SAFETEA-LU: Safe Accountable Flexible Efficient Transportation Equity Act: Legacy for Users. United States Department of Transportation/Federal Highway Administration. Retrieved 24 August 2006 from, <http://www.fhwa.dot.gov/safetealu/legis.htm>

Agranoff, Robert J. (1986). Intergovernmental Management: Human Services Problem Solving in Six Metropolitan Areas. Albany, NY: State University of New York Press.

Agranoff, Robert and McGuire, Michael (1998). "A Jurisdiction Based Model of Intergovernmental Management in U.S. Cities." Publius: The Journal of Federalism.

Alberta Public Interest Research Group (2005). Consensus Decision Making Process. Retrieved 17 November 2007 from, <www.apirg.org/downloads/ formsold/consensus.pdf>.

Baltimore Metropolitan Council (2006) (a) About the Baltimore Regional Transportation Board. Retrieved 7 November 2006 from, <http://www.baltometro.org/content/view/19/146>.

Baltimore Metropolitan Council (2006) (b). Congestion Management. Retrieved 7 November 2006 from, <http://www.baltometro.org/content/view/46/151/>. 
Baltimore Metropolitan Council (2006) (c) Transportation Management. Retrieved 7 November 2006 from, < http://www.baltometro.org/content/view/83/149/>. Bendoly, Elliot and Swink, Morgan. "Moderating Effects of Information Access on Project Management Behavior, Performance and Perceptions." Journal of Operations Management 25 (2007), 604-622.

Benson, Robert (7 April 1999). "Sustainable Industry Program Offers a New Approach to Environmental Policy." Retrieved 3 November 2007 from <http://govinfo.library.unt.edu/npr/library/announc/040899.html>.

Bloomington Metropolitan Planning Organization (8 June 2007) (a). Unified Planning Work Program, Fiscal Year, Fiscal Year 2008. Retrieved 12 November 2007 from <http://bloomington.in.gov/egov/apps/document/center.pl?path $=$ doc\&id $=26660 \& i d 2=24565 \&$ linked $=0 \& f D D=302-1306>$.

Bloomington Metropolitan Planning Organization (2007) (b). Metropolitan Planning Organizations' Citizens Advisory Committee. Retrieved 30 November 2007 from <http://bloomington.in.gov/planning/mpocac.php>.

Brännback, Malin, Carsrud, Alan, and Krueger, Norris (2007). “The 'Molecular Biology' of Regional Innovation Systems." Research Papers in Business Studies from Åbo Akademi University.

Bryan Park Interchange Advisory Committee (October, 1999). Final Report and Recommendations. Retrieved 30 November 2007 from $<$ http://www.virginia.edu/ien/docs/BPIAC_Final.pdf>.

Burton, Richard M., DeSanctis, Gerardine, and Obel, Bǿrge (2006). Organizational Design: A Step-by-Step Approach. New York, NY: Cambridge University Press, 2006.

Carmichael, David G (2002). Disputes and International Projects. Exton, PA: A.A. Balkema Publishers.

Chisholm, Donald (1989). Coordination Without Hierarchy: Informal Structures in Multiorganizational Systems. Los Angeles, CA: University of California Press,.

Dyer, Caroline (1999). "Researching the Implementation of Educational Policy: a Backward Mapping Approach." Comparative Education: Volume 35, Number 1. 
Federal Highway Administration. Building Congestion Partnerships to Support the Vital Few (2006). United States Department of Transportation/Federal Highway Administration. Retrieved 7 September 2006 from, <http://www.fhwa.dot.gov/ congestion/partners.htm\#whatisit>.

Hauck, Allan J., Walker, Derek H.T., Hampson, Keith D., and Peters, Renaye J (January/February, 2004). "Project Alliancing at National Museum of Australia: Collaborative Process." American Societyof Civil Engineers: Journal of Construction Engineering and Management.

HNTB and Hendricks County, Indiana (2005). Ronald Reagan Corridor Master Plan. HNTB. Retrieved August 2007 from <http://www.brownsburg.org/ egov/docs/1139317419394.htm>.

Holmes, Brenda L. (26 April 2007). "New I-74 Interchange should make roads safer." Community Newspaper Holdings, Inc. Retrieved 16 November 2007 from, $<$ http://www.hgazette.com/cnhins/generalnews/cnhinsgeneralnews_story_1160 95620.html>.

Huxham, Chris and Vangen, Siv (2005). Managing to Collaborate: The Theory and Practice of Collaborative Advantage. New York, NY: Routledge.

Indiana Department of Transportation (2007). 2030 Long Range Transportation Plan. Retrieved 12 November 2007 from, < http://www.in.gov/indot/5341.htm>. Indiana Metropolitan Planning Organization Council (17 April 2007). Indiana MPO Council Handbook. Retrieved 19 April 2007 from, <http://www.indianampo.com/PDF/INDIANA\%20MPO\%20HANDBOOK.pdf> Kentucky Transportation Cabinet. Statewide Transportation Planners Manual, Fiscal Year 2007.Frankfort, KY: Kentucky Transportation Cabinet Division of Planning. 17 March 2007.

Kerrigan, Shelia (September, 2004). How to Use a Consensus Process to Make Decisions. Community Arts Network. Retrieved 17 November 2007 from, $<$ http://www.communityarts.net/readingroom/archivefiles/2004/09/how_to_use_ a_co.php>.

Kraus, William A (1980). Collaboration in Organizations: Alternatives to Hierarchy. New York, NY:Human Sciences Press, Inc. 
Lynch, Robert Porter (1989). The Practical Guide to Joint Ventures and Corporate Alliances:How to Form, How to Organize, How to Operate. New York, NY: John Wiley and Sons.

Mertz, W.L. and Ritter, Joyce (14 March 2006). Building the Interstate. Federal HighwayAdministration. Retrieved 16 November 2007 from, $<$ http://www.fhwa.dot.gov/infrastructure/build.pdf>.

National Policy Consensus Center (2006). Transportation Collaboration in the States. Retrieved 13 November 2006.from, <http://www.policyconsensus.org/ publications/reports/docs/TransportationCollaboration.pdf>.

Peters, B. Guy and Pierre (2003), Jon. Handbook of Public Administration. London, England.Sage Publications.

Plainfield, Indiana Department of Engineering (8 October 2007). 2007 Road Projects for Plainfield. Retrieved 16 November 2007 <from,http://townofplainfield.com/ main/index.php?dept=2\&action=26\&id=1168>

Section 133: Surface Transportation Program. Retrieved 4 November 2006 from, <http://www.washingtonwatchdog.org/documents/usc/ttl23/ch1/sec133.html> TEA-21 - Transportation Equity Act for the 21st Century (8 July 2002). United States Department of Transportation. Retrieved 27 August 2006 from, $<$ http://www.fhwa.dot.gov/tea21/legis.htm>

The Common Place (23 January 2005). Consensus Decision Making. Retrieved 17 November 2007 from, <http://www.thecommonplace.org.uk/ information.php?page=articles\&ilD=4>.

Tinnirello, Paul C (2002) New Directions in Project Management. Washington, D.C.: Auerbach Publications.

United States Environmental Protection Agency (1994). Sustainable Industry Project: Promoting Strategic Environmental Protection in the Industrial Sector, Phase 1 Report: The Metal Finishing Industry. Washington, D.C.: United States Environmental Protection Agency.

United States Department of Transportation/Federal Highway Administration. TEA-21: Transportation Equity Act of the $21^{\text {st }}$ Century: Fact Sheet. Retrieved 5 November 2006 from, <http://www.fhwa.dot.gov/Tea21/factsheets/stp.htm>. 
Wastach Front Regional Council (2006). Wastach Front Regional Council Congestion Management System. Retrieved 25 September 2006 from, <http://www.wfrc.org/programs/cm.htm>.

Wikipedia: The Free Encyclopedia (2007). “Image:Double Helix.png." Retrieved 30 October 2007 from < http://commons.wikimedia.org/wiki/lmage:Double_Helix. png>.

Williams, Walter, Elmore, Richard F., Hall, John Stuart, Jung, Richard, Kirst, Michael, MacManus, Susan A., Narver, Betty Jane, Nathan, Richard P., and Yin, Robert K. (1982). Studying Implementation: Methodological and Administrative Issues. Chatham, New Jersey. Chatham House Publishers, Inc.

Wilmington Area Planning Council (5 May 2005). "WILMAPCO Congestion Management System." Retrieved 25 September 2006 from, <http://www.wilmapco.org/cms/2005\%20CMS\%20FINAL.pdf>.

Wilmington Area Planning Council (2006). "WILMAPCO Council." Retrieved 25 September 2006 from, < http://www.wilmapco.org/Council/index.htm>. 